\title{
Vibration and Stability of 3000-hp, Titanium Chemical Process Blower
}

\author{
Les Gutzwiller \\ Robinson Industries, Inc., Zelienople, Pennsylvania, USA
}

\author{
Mark A. Corbo \\ No Bull Engineering, Guilderland, New York, USA
}

This 74-in-diameter blower had an overhung rotor design of titanium construction, operating at 50 pounds per square inch gauge in a critical chemical plant process. The shaft was supported by oil-film bearings and was directdriven by a 3000-hp electric motor through a metal disk type of coupling. The operating speed was $1780 \mathrm{rpm}$. The blower shaft and motor shaft motion was monitored by Bently Nevada proximity probes and a Model 3100 monitoring system.

Although the blowers showed very satisfactory vibration levels during test runs at the manufacturer's plant, the vibration levels in situ had always been higher than was desirable. After several months of monitoring showed ever increasing vibration levels, one of the blowers was shut down in order to diagnose and resolve the problem.

Several steps were taken to diagnose the problem: (1) The rotor was removed and the shop balance was checked and corrected. (2) The bearing support movement due to thermal expansion was measured. Then the shafts were misaligned in the cold condition in order to achieve near-perfect shaft alignment during normal operation. (3) The expected shaft vibration at the bearings was determined using lateral rotor dynamics analysis, including critical speed mapping. (4) A heavy sleeve was added to the blower shaft to increase the radial load on the drive-end bearing. (5) The metal disk type of coupling was replaced by a gear coupling. (6) The finite element and impact of the bearing support pedestal were tested to determine the stiffness of the bearing support. (7) The shaft movement was measured during a coast-down. (8) Tilting-pad bearings were evaluated as a possible replace-

Received 20 April 2001; accepted 18 October 2001.

Address correspondence to H. Leslie Gutzwiller, Robinson Industries, Inc., 400 Robinson Drive, Zelienople, PA 16001. E-mail: lgutzwil@ robinsonfans.com ment for the original standard sleeve type of hydrodynamic oil-film bearings.

The final solution showed the importance of coupling angular stiffness (often rarely considered in machine design), rotor dynamic analysis, and field alignment. $\begin{array}{ll}\text { Keywords } & \begin{array}{l}\text { Blower, Chemical process, Fluid-film bearing, Titanium, } \\ \text { Vibration }\end{array}\end{array}$

A major chemical manufacturer in the southern United States operates a process that involves the moving of wet chlorine gas. The system operates at a background pressure of up to 100 pounds per square inch gauge (psig). A very heavy-duty process gas blower increases the pressure of the gas by approximately 6.5 pounds per square inch (psi) while circulating a volume of 57,500 cu ft per min. This process must run for long periods of time with minimal shutdowns to maximize the profitability of the operation. Two blowers operate in parallel and each provides recirculation of the gas, as described. A 3000-hp, $1780 \mathrm{rpm}$, constant-speed AC motor drives the blower through a metal disk coupling. The blower (Fig. 1), is configured with two plain cylindrical sleeve bearings and an overhung blower rotor inside an extremely heavy-duty blower housing. The blower rotor is fabricated entirely of titanium grade 7 and the housing is 6-in-thick mild steel with titanium "wallpaper" inside to provide effective corrosion resistance.

The entire blower and motor assembly, designed and fabricated by Robinson Industries, rests on an integral sub-base that is grouted to a heavy concrete foundation. Lubrication for the blower and motor bearings is supplied by a circulating oil system that provides filtered and constant-temperature lubricant. The blower is monitored by means of (1) a fixed (outboard) bearing in the blower that includes two radia- and one axialvibration proximity probes and one platinum (RTD) temperature detector; (2) float (inboard) bearing in the blower that includes two radial vibration proximity probes and one platinum RTD 


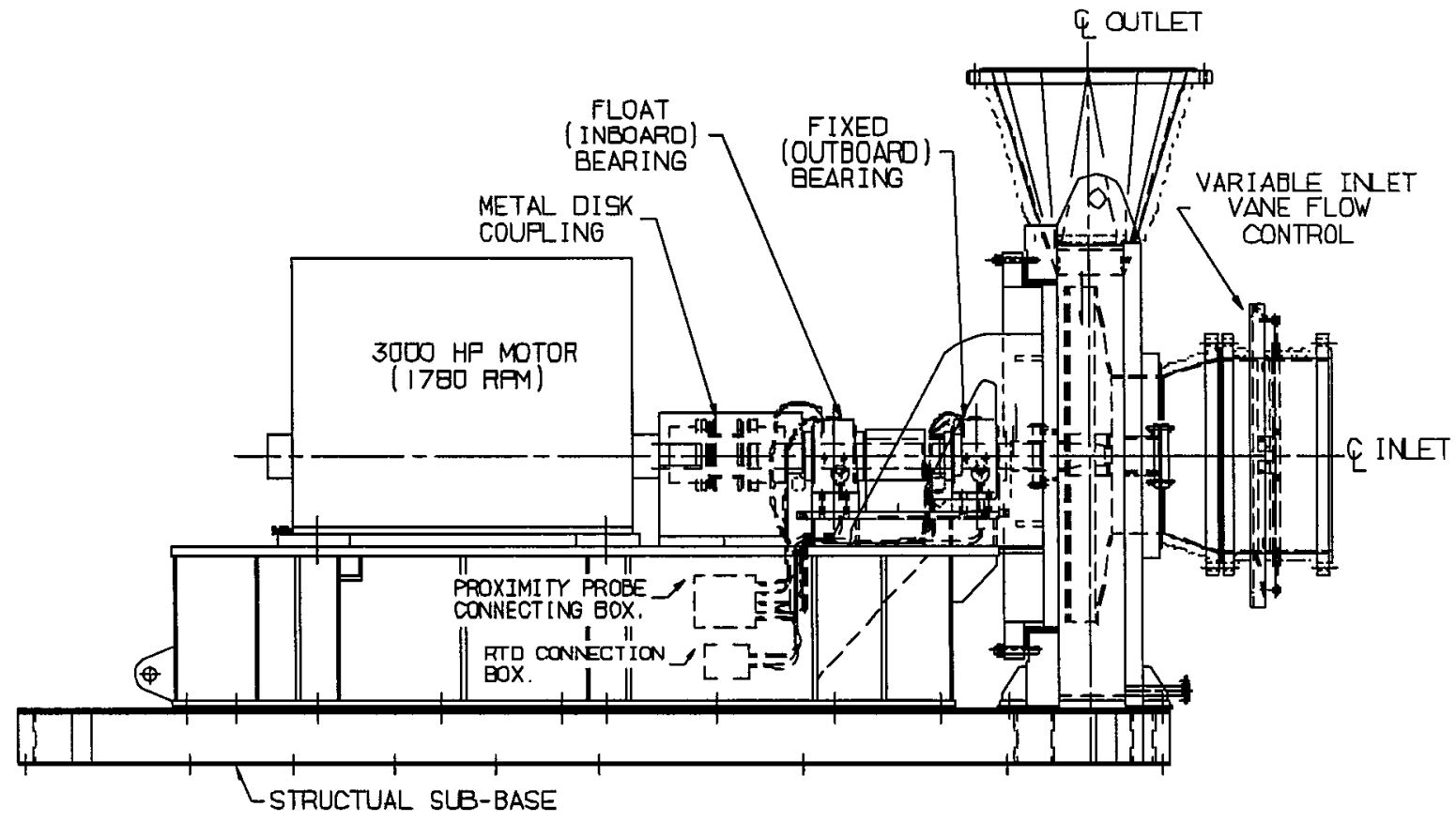

FIGURE 1

The general assembly of the blower.

temperature detector; and (3) a fixed bearing in the motor (opposite the coupling) with two radial-vibration proximity probes. All of these measured parameters are continuously monitored using a Bently Nevada model \#3100 monitoring system.

The blower volume is controlled by means of a variableinlet vane damper of titanium grade 7 that was supplied by the blower's manufacturer. It is essential during operation of these blowers that no chlorine gas escape into the atmosphere. A multring carbon shaft seal with a titanium grade 7 housing is used to provide the shaft's sealing. This included a combined steam purge and nitrogen purge to ensure that the shaft surfaces remain wet and that no steam or chlorine gas escapes to the atmosphere.

\section{PREINSTALLATION TESTING}

Because of the critical nature of this process, the blowers were carefully checked for accuracy of manufacturing, and extensive testing was done at the manufacturer's plant prior to shipment. This included shaft runout checks to ensure that the mechanical runout was less than 0.0005 in. Balancing was done to meet the (AMCA)-204-96 Grade G2.5 requirement. The blowers were checked for air performance in the manufacturer's AMCAregistered laboratory, and a mechanical run test of several hours' duration ensured that the vibration levels, as measured with the proximity probes, were satisfactory prior to shipment. Note that the mechanical run testing was done with a smaller motor and a gear coupling. This was necessary because it was impractical to run the actual 3000-hp motor that would be used in the field.

In addition, the blower was operated in a closed-loop system set up at the blower manufacturer's facility so as to ensure the satisfactory operation of the blower in conjunction with the other critical-process equipment. This testing confirmed that the performance requirements of the blowers matched the actual performance requirements in the system at the end-user's plant. All testing went well. Proximity-probe readings from the blower bearings showed a maximum 1.4 mils displacement, peak to peak (pp) during the mechanical run test. The bearings were disassembled after the mechanical run test, and inspection revealed no evidence of any damage or rubbing.

\section{INSTALLATION AND START-UP}

The blowers were shipped to the job site disassembled. This ensured that no damage would be done to the bearing liners during shipment. The blowers were assembled and installed on a heavy foundation using epoxy grout and under the watchful eye of both the end user and the blower supplier. The units were properly installed, with expansion joints immediately adjacent to the blower inlet and discharge flanges to ensure minimal piping loads on the blower housing. The field installation included alignment and installation of the metal disk couplings that had been specified originally. The blowers were started, and it was immediately noticed that the vibration levels of the blower were substantially higher than they had been during the mechanical run testing at the factory. However, the blowers continued to operate marginally for approximately 8 months before more serious trouble began to occur. It was noted that the vibration amplitude of the shaft, especially on the blower float (inboard) bearing, began to rise, and it grew gradually worse. Eventually, the unit had to be shut down because of the intense vibrations. Upon 


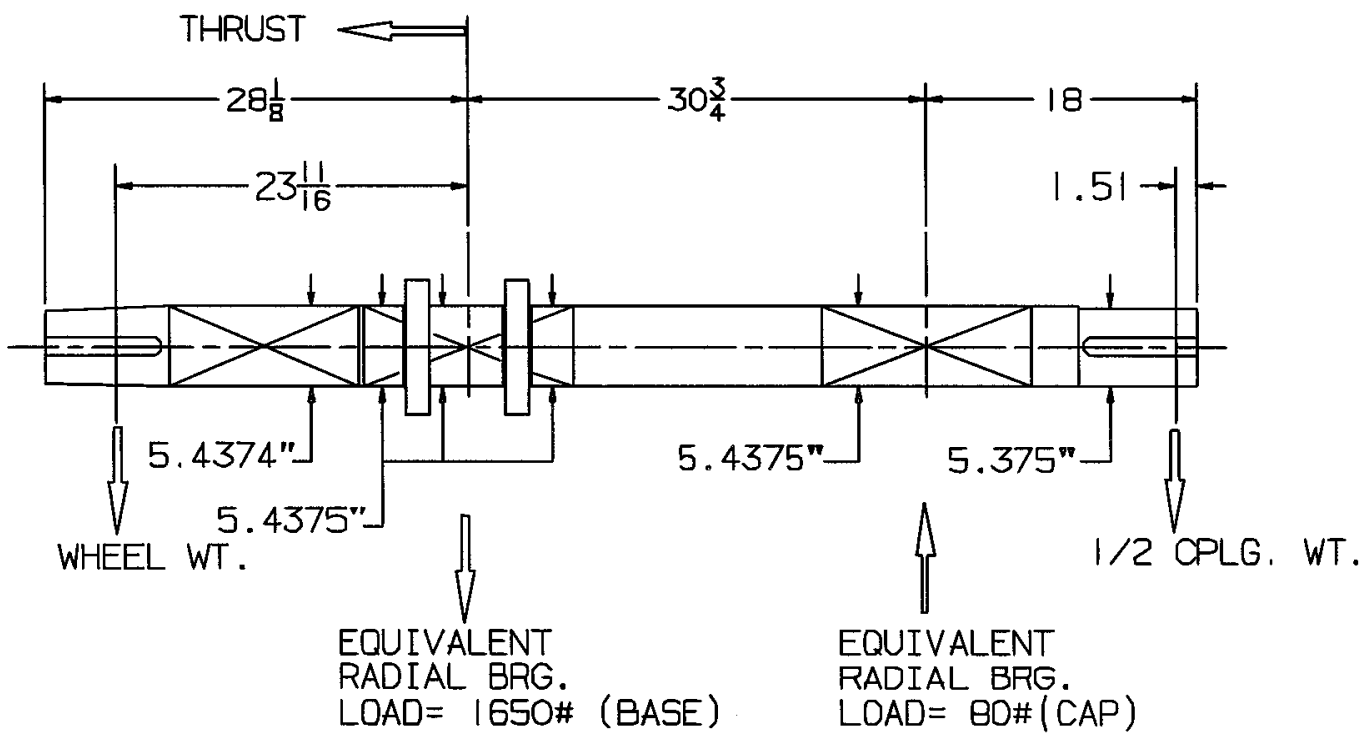

FIGURE 2

Bearing and shaft loading.

inspection of the bearings, it was found that the float (inboard) bearing showed little or no damage. However, the bearing liner on the more heavily loaded impeller side of the blower was badly spalled, and pieces of the babbitt had actually broken away from the liner casting. (Fig. 3A, B, and C.) In addition, it was found that the shaft had rubbed the titanium carbon ring-seal housing, causing damage to the shaft and to the seal. This led to a review of the bearing loadings. Figure 2 shows the shaft and bearing configuration as well as the radial and axial loads during normal operation.

There was concern that the float (inboard) bearing was so lightly loaded that it might be unstable. An investigation revealed that there could have been some release of chlorine gas

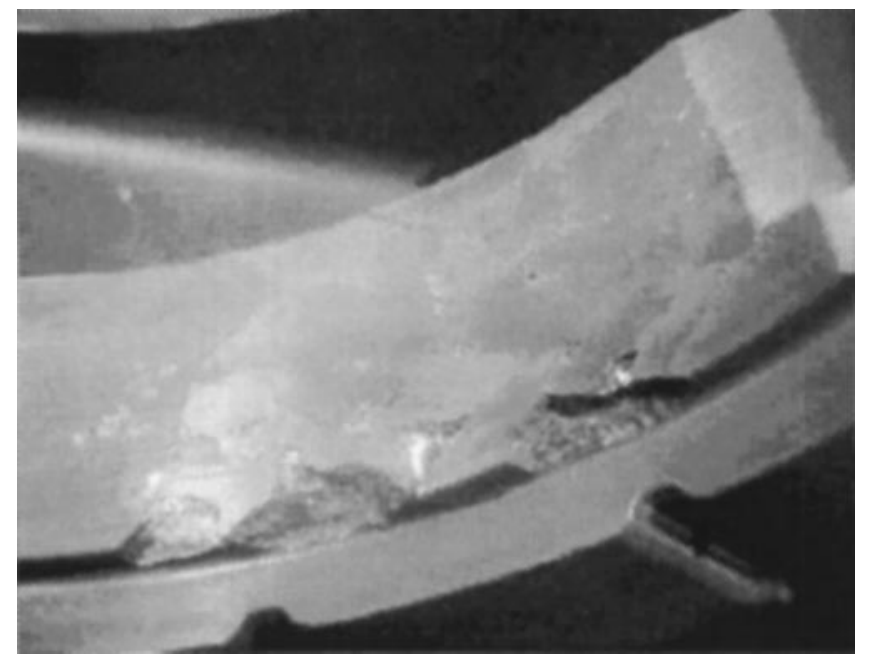

FIGURE 3A

A close-up of fixed (outboard) sleeve bearing, upper half. that may have contaminated the oil supplied to the fixed (outboard) bearing. Some felt that this might be a cause of the bearing liner failure. At the same time, an investigation was performed to determine, as accurately as possible, the presence and amount of any thermal expansion that could affect the alignment of the motor shaft and the blower shaft. Although the blower typically operates at only $115^{\circ} \mathrm{F}$, the readings taken in the field seemed to show that the base of the blower bearing expanded vertically considerably more than did the motor base. The repairs were made as required and the blower was reassembled. Because of the concerns noted above, three important changes were made in the set up of this blower: (1) A heavy, walled, steel sleeve was clamped into place around the shaft between the two blower

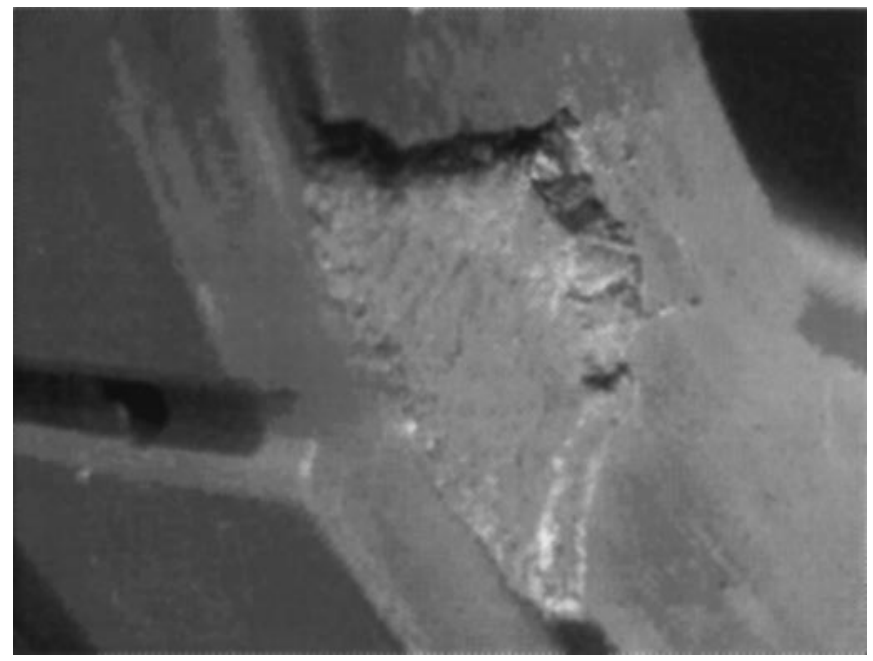

FIGURE 3B

A close-up of fixed (outboard) sleeve bearing, upper half. 


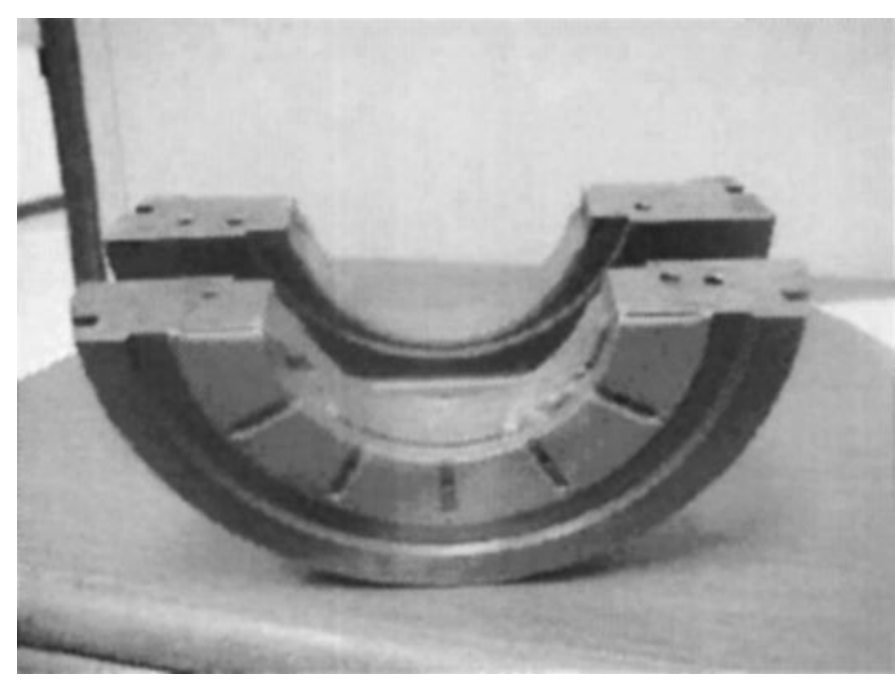

FIGURE 3C

A side view of the fixed (outboard) sleeve bearing, upper half.

bearings. The purpose of this sleeve was to increase the downward load on the drive-side bearing. However, this provided no improvement, which was later confirmed analytically. (2) The motor was purposely set up to be considerably higher than the blower shaft and at a skewed angle while the machine was at ambient temperatures. This was done in the hope that the motor shaft and blower shaft would be nearly perfectly aligned under normal operating conditions. (3) The running clearance between the titanium shaft seal housing and the blower shaft was increased to provide more tolerance for possible thermal expansion of the blower housing during normal operation. After these changes had been made, bearing failures associated primarily with the blower's fixed (outboard) bearing continued on both blowers, and at a more rapid pace.
Additional studies were done to determine as accurately as possible the stiffness of support elements of the motor and the bearing. By using finite element analysis, the pedestal stiffness was determined to be greater than $5.0 \times 10^{6}$ pounds per in (both vertical and horizontal). Field impact testing showed a stiffness of $2.0 \times 10^{6}$ pounds per in vertically. These data were then considered by Kelm Engineering in conjunction with a rotor dynamics model to determine the expected shaft responses to unbalance as a function of the operating speed and the bearing support stiffness (Kelm 2000). This analysis actually used a pedestal stiffness $1 \times 10^{6}$ pounds per in horizontally and $2 \times 10^{6}$ pounds per in vertically, and also included the effects of the stiffness and damping of the plain sleeve bearing an oil film. However, this analysis was done on the blower shaft only, excluding any of the rotating elements associated with the coupling or motor. The results of the analysis (Figs. 4 and 5) indicated that this machine should have operated satisfactorily with this shaft and bearing loading at the normal operating speed of $1780 \mathrm{rpm}$.

The forced-response analysis of the unbalance (assuming AMCA 204-96 level G2.5 unbalance of 10.9 oz-in showed an expected shaft movement of approximately 1.30 mils at the float (inboard) bearing and of approximately 0.45 mils at the fixed (outboard) bearing. It was therefore difficult to understand why there were continued bearing failures, when this appeared to be a satisfactory design. Unfortunately, this model did not accurately predict the relatively high vibration of 3.0 to 5.0 mils pp that was typically observed at the float (inboard) bearing location (Fig. 6).

\section{ANALYSIS OF THE ROOT CAUSE OF THE FAILURE}

A meeting of all parties was held to investigate the possible root causes of the bearing failures in these critical-process blowers. Although it was not possible to narrow the potential problems down to a single root cause at this meeting, many suspected problems were eliminated as candidates. This led to the

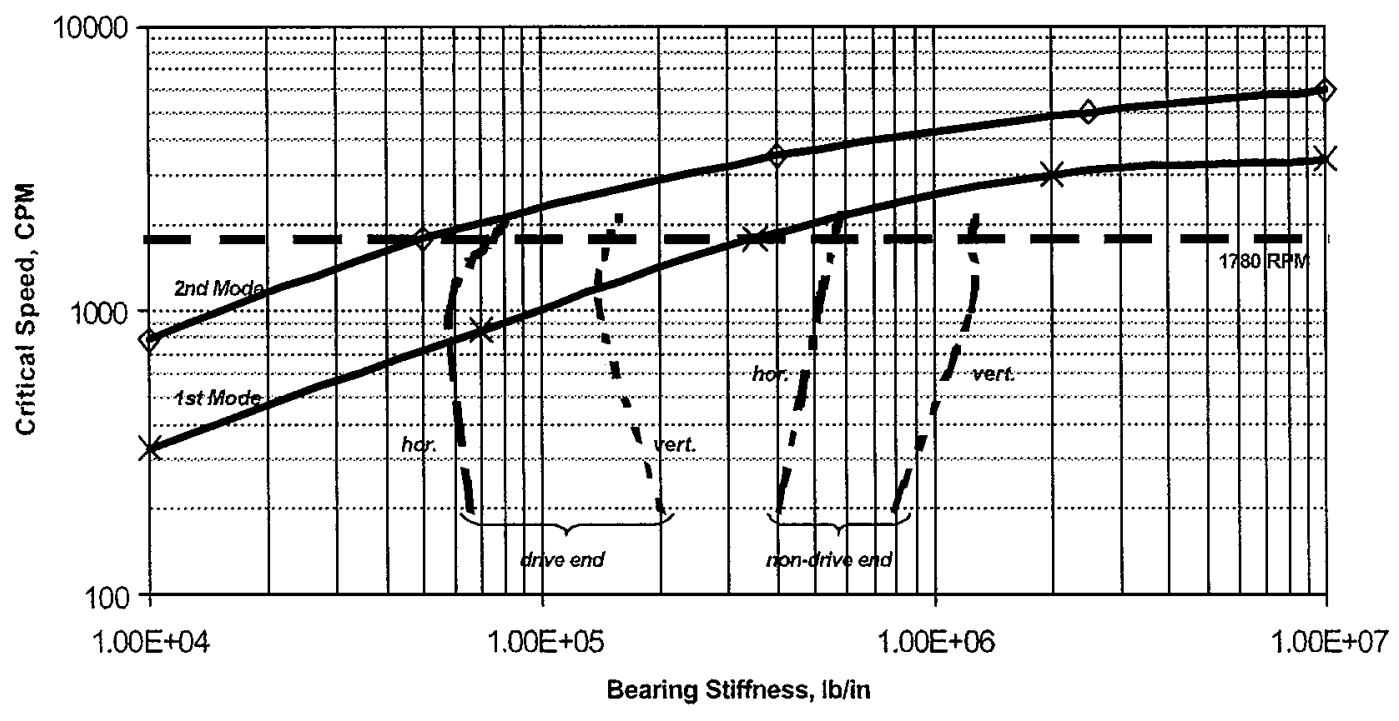

FIGURE 4

Undamped critical speed map, original design bearings. From a report by Kelm Engineering dated 10-1-2000. 


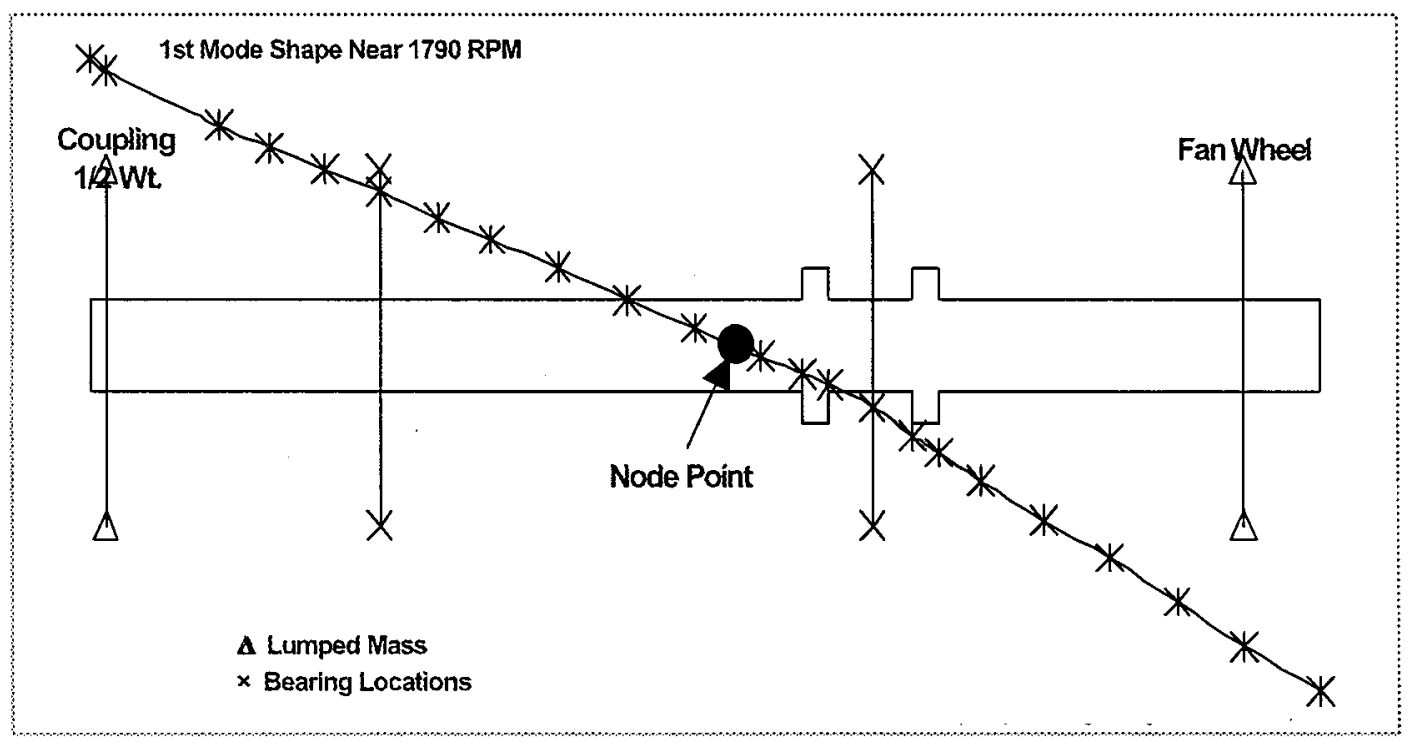

FIGURE 5

Rotor cross-section. From report by Kelm Engineering dated 10-1-2000.

targeting of three primary causes of the problem that required additional investigation and follow-up.

\section{Angular Stiffness}

It was noted that the angular stiffness of the metal disk coupling was extreme. It was felt that this might make the critical speed map analysis (which included only the blower shaft and rotor) invalid. Field data that had been gathered showed that the amplitude of vibration at the blower float (inboard) bearing actually increased almost linearly from the maximum $1780 \mathrm{rpm}$ operating speed down to $0 \mathrm{rpm}$. Vibration data were collected during the coastdown of the rotor, and additional information was gathered during a slow roll with the motor not in operation
(Fig. 7). This was, of course, most unusual as vibration amplitude typically decreases with decreasing operating speed. The shaft movement at the blower fixed (outboard) bearing did not increase with decreasing speed. This led to the conclusion that the metal disk coupling (with an angular stiffness of 20,094 inlbs/degree could somehow be contributing to the failures of the blower's bearings.

\section{Alignment}

A review of the alignment history of these blowers showed that at times the motor shaft was set 0.012 in higher than the blower shaft under the ambient start-up conditions. This is rather extreme for a thermal growth allowance. There was concern that

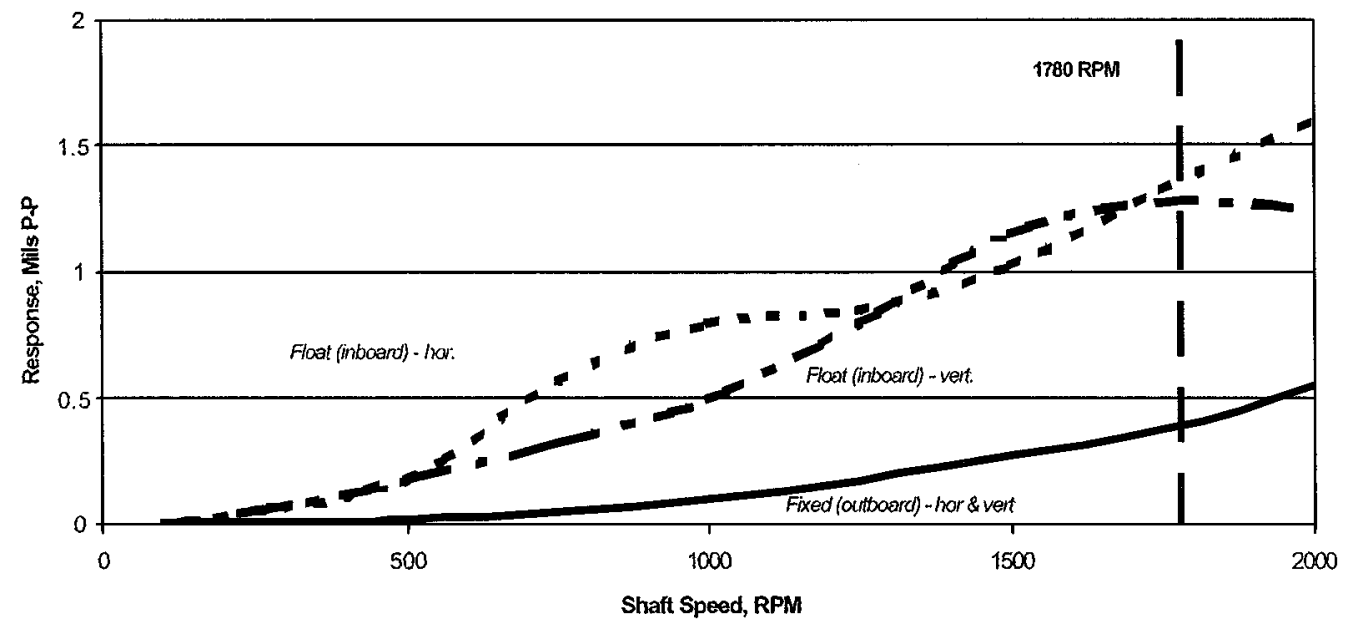

FIGURE 6

Unbalanced response; original bearings, ANSI G2.5 unbalance of 10.9 oz-in. From a report by Kelm Engineering dated 10-1-2000. 


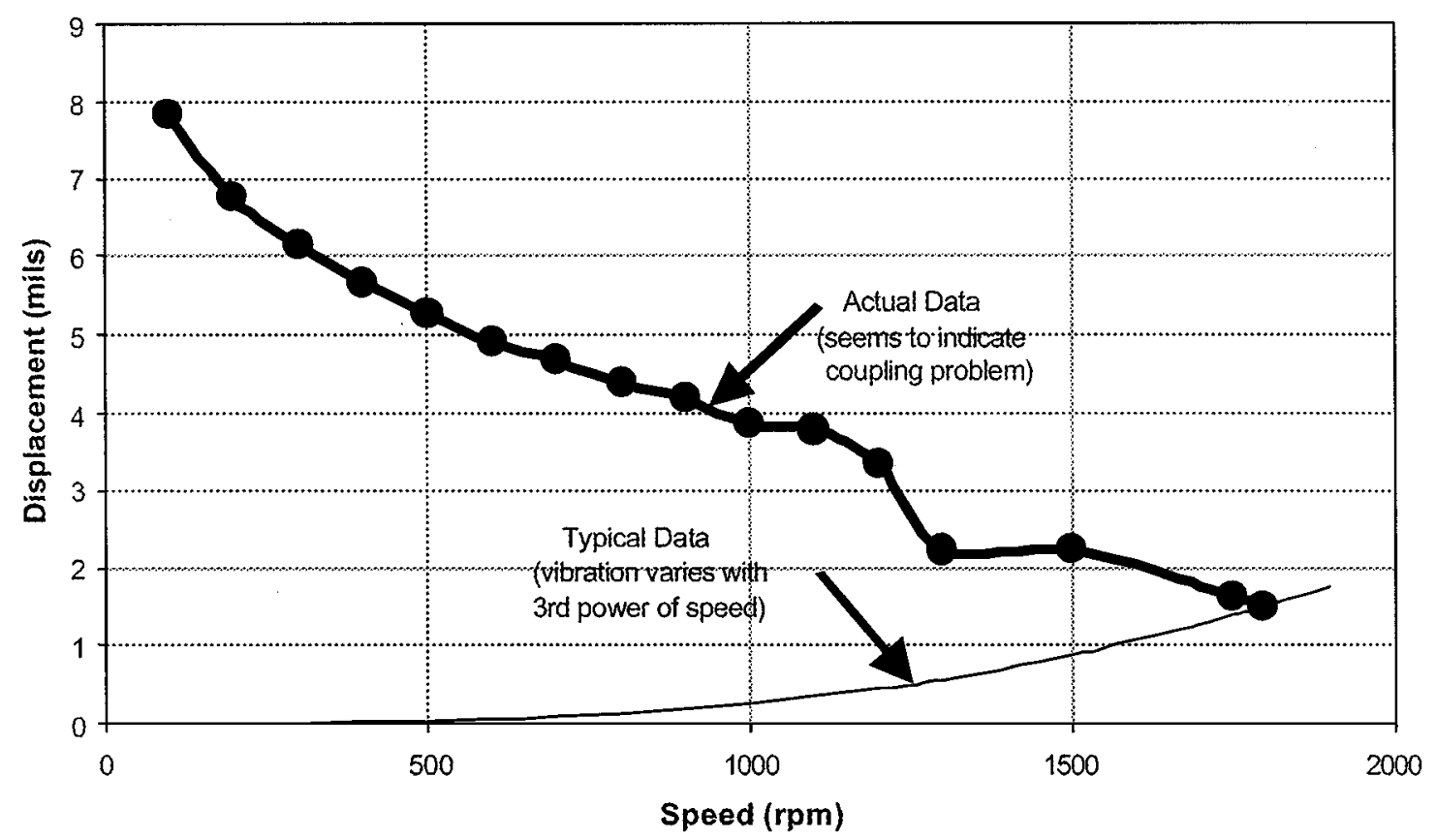

FIGURE 7

Vibration versus speed during coastdown.

such a misalignment at the ambient condition combined with a coupling that has high angular stiffness could lead to a blower bearing preload during the ambient start-up conditions. Such a preload may result in immediate damage to the bearing, even if the shafts eventually go into proper alignment at normal operating temperatures. It also appeared to this author that the alignment values (to compensate for thermal expansion of the bearing and motor base) were extreme compared to historical data concerning blowers of this type-especially with an operating temperature of only $115^{\circ} \mathrm{F}$.

It should be noted that because of the concerns about the angular stiffness of the metal disk coupling and the ambient alignment procedure, a gear coupling was used instead. The gear coupling would practically eliminate concerns about the angular stiffness of the coupling and would mechanically separate the motor shaft from the blower shaft more effectively. An initial attempt at using a gear coupling resulted in a bearing failure after only 1 week of operation. However, those bearings had been rebabbitted on an emergency basis, and there was some question about the condition of the bearing liners at start-up. Subsequent operation with the gear coupling in place resulted in considerably longer and more satisfactory operating campaigns.

\section{Rotor Dynamics Analysis}

Because of the light loading on the blower float (inboard) bearing, it was recommended that a rotor dynamics analysis be done on the complete blower-coupling-motor system. The angular stiffness of the coupling would be included in the analysis. Although the blower fixed (outboard) bearing had been the bearing that failed, the blower float (inboard) bearing had historically exhibited higher shaft movement and seemed to be a precursor of forthcoming fixed (outboard) bearing failures. The light loading on the fixed (outboard) bearing was potentially a cause for instability (see Fig. 2). It was recommended that an analysis of the complete rotating system, including blower rotor, coupling, and motor rotor be performed. It was thought that the rotor dynamics of the complete system should show whether this light loading was, in fact, a major problem. If instability (or overly sensitive unbalance response) were evident, it might have been possible to replace the plain sleeve bearings with tilting pad bearings which have preload capability and higher damping characteristics) to provide more stabilization of the blower shaft.

\section{ROTORDYNAMICS}

A consultant, No Bull Engineering of Guilderland, NY, was contracted to perform lateral and torsional rotordynamic analyses of the existing and revised blower systems (Corbo and Malanoski 1996, 1998). The consultant proceeded with the following tasks: (1) lateral rotordynamic analysis of the original blower with the metal disk coupling; (2) lateral rotordynamic analysis of the blower with the new gear coupling; (3) lateral rotordynamic analysis of the blower with the new gear coupling and tilting-pad bearings; (4) torsional vibration analysis of the original blower with the metal disk coupling; and (5) torsional vibration analysis of the blower with the new gear coupling.

\section{Lateral Analysis Using the Metal Disk Coupling Overview of the Rotordynamic Analysis}

The first task undertaken in the lateral analysis by No Bull Engineering was the creation of a comprehensive rotordynamic 


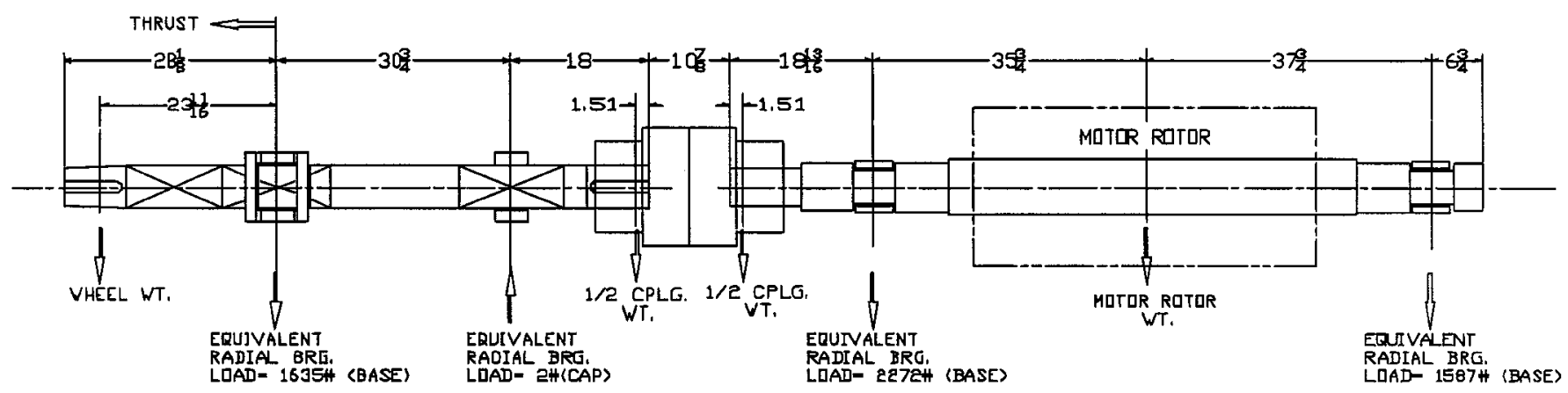

FIGURE 8

Blower and motor bearings; blower and motor shafts static loading.

model for the entire system, consisting of the motor shaft, the metal disk coupling, and the blower shaft. A schematic of this model is presented in Figure 8.

This was in direct contrast to all prior analyses, which had treated the motor and blower as two separate, independent systems, from a lateral rotordynamics standpoint. Although this is fairly standard practice for the lateral rotordynamic analysis of machinery components that are joined by so-called flexible couplings, several pieces of empirical evidence indicated that this was not the best approach for this machine:

1. The vibration at the motor's float (inboard) bearing seemed to track that of the blower's float (inboard) bearing. Whenever one was relatively high, so was the other. In fact, in almost all instances in which the blower's fixed (outboard) bearing failed, the failure was immediately preceded by high vibrations at both the blower and motor float (inboard) bearings.

2. When the blower was shop-tested using a gear coupling, which would truly divide the machine into two independent components, the blower float (inboard) bearing vibrations were fairly low (about 1.4 mils pp). However, upon initial commissioning at the plant, with the disk coupling in place, the vibrations jumped up to a relatively high level (about 4.7 mils pp).

3. At one point when the blower vibrations were high, the unit was shut down and the motor was then run uncoupled from the blower. The motor's float (inboard) bearing vibrations at running speed, which had been 4.7 mils pp immediately prior to shutdown, were observed to drop to 0.4 mils $\mathrm{pp}$ when run uncoupled.

4. After experiencing several bearing failures, maintenance personnel shut down the machine when it was, once again, experiencing high vibrations at the blower float (inboard) bearing and replaced the disk coupling with a gear coupling. Upon restart, two distinct improvements in the vibratory behavior were observed. First, the running speed vibrations at the blower float (inboard) bearing instantaneously dropped from about 4.5 to about 1.5 mils pp. Second, the coast-down problem in which the vibrations increased linearly as speed decreased (Fig. 7), a problem that had consistently plagued both blowers since their commissioning, suddenly disappeared. Instead, during coast-downs, the vibrations displayed much more conventional behavior.

All of these observations suggested that with the disk coupling installed, the motor and blower were not behaving as two independent systems, from a rotordynamics standpoint. Instead, there was strong evidence that the machine was behaving as a single comprehensive rotordynamic system in which the motor and blower vibrations were anything but independent of one another. This hypothesis was reinforced by the impressive size of the disk coupling and its relatively high reported angular stiffness (20,094 in-lbs/degree).

\section{Bearing Static Loading Analysis}

Once the comprehensive rotordynamic model was generated, it was employed in a static loading analysis of the bearing that used a proprietary computer code that determines the static loadings on any number of beam supports for various loading and alignment conditions. Although seven different alignment conditions were evaluated, the first case investigated was the perfectly aligned case in which both motor bearings are assumed to be in perfect alignment with both blower bearings.

The case of perfect alignment was used to perform a study of the sensitivity of the bearing loads to the assumed stiffness at the blower float (inboard) bearing; the results are presented in Table 1. For this study, the other three bearings' stiffnesses were held constant at representative values while the blower float (inboard) bearing's stiffness was varied.

The results of this study were enlightening. Whereas the loads on the other three bearings were essentially independent of the assumed blower float (inboard) bearing stiffness, the critical load on the blower float (inboard) bearing was extremely sensitive to this variation. For relatively high values of bearing stiffness, the float (inboard) bearing load was found to be in the vicinity of the value used in the previous rotordynamic analysis (80 lbs). However, if the stiffness was assumed to be relatively low, which is highly likely since this bearing is known to be lightly loaded, the bearing load dropped precipitously, all the way down to $1 \mathrm{lb}$ ! 
TABLE 1

Bearing Radial Loads as a Function of the Blower Float (Inboard) Bearing Stiffness (Perfect Coupling Alignment Assumed)

\begin{tabular}{lcccc}
\hline $\begin{array}{c}\text { Blower float (inboard) } \\
\text { bearing oil-film } \\
\text { stiffness (lb/in) }\end{array}$ & $\begin{array}{c}\text { Motor fixed (outboard) } \\
\text { bearing load } \\
(\mathrm{lb})\end{array}$ & $\begin{array}{c}\text { Motor float (inboard) } \\
\text { bearing load } \\
(\mathrm{lb})\end{array}$ & $\begin{array}{c}\text { Blower float (inboard) } \\
\text { bearing load } \\
\text { (lb) }\end{array}$ & $\begin{array}{c}\text { Blower fixed (outboard) } \\
\text { bearing load } \\
\text { (lb) }\end{array}$ \\
\hline $1.0 \times 10^{2}$ & 1590 & 2260 & -1 & 1628 \\
$5.0 \times 10^{2}$ & 1590 & 2261 & -1 & 1628 \\
$1.0 \times 10^{3}$ & 1590 & 2261 & -2 & 1629 \\
$1.5 \times 10^{3}$ & 1590 & 2262 & -17 & 1629 \\
$1.0 \times 10^{4}$ & 1587 & 2272 & -82 & 1635 \\
$1.0 \times 10^{5}$ & 1575 & 2321 & -133 & 1664 \\
$1.0 \times 10^{6}$ & 1566 & 2359 & -142 & 1690 \\
$1.0 \times 10^{7}$ & 1564 & 2365 & & \\
\hline
\end{tabular}

It should be noted that the minus signs employed in this table merely reflect the fact that the bearing is cap-loaded.

This study pointed out a fundamental weakness in the previous analyses that treated the blower and motor as independent systems. Because the blower is supported on only two bearings, when it is treated as an independent system, it is a statically determinate system. This means that the calculated load acting on the float (inboard) bearing is totally independent of the bearing's stiffness. Accordingly, even if the stiffness is as low as $100 \mathrm{lb} / \mathrm{in}$, the analysis will still yield the same bearing load of $-80 \mathrm{lb}$.

However, when the entire system is analyzed, two more supports (the motor's two bearings) are introduced into the system. This changes the system to a statically indeterminate system, in which the flexibility of the supports, as well as that of the shafting, determines the load distribution. Because the other three bearings are known to be significantly stiffer than the lightly loaded blower float (inboard) bearing, they have a tendency to reduce the load on that bearing considerably. The result is that the load on the bearing is likely to be ligher than the 80-lb load employed in all previous analyses.

Once the static loading model of the bearing was set up, it was used to determine the bearing load distribution for seven alignment cases - the perfectly aligned case (case 1) and six alignment cases that were employed at various times on the blowers. This analysis was iterative since the blower float (inboard) bear- ing's stiffness is dependent upon its loading (an implicit characteristic of plain cylindrical bearings) while, as shown in Table 1, the load is also highly dependent on the assumed stiffness. Accordingly, the blower float (inboard) bearing's load and stiffness were iterated until a converged solution was reached. The results for all seven alignment cases are presented in Table 2.

Examination of the table reveals that for all cases except case 6, the blower float (inboard) bearing load is at least one order of magnitude less than the previously assumed value of $80 \mathrm{lbs}$. The reason for this, as discussed earlier, is that the introduction of the two motor bearings into the picture changed the system from statically determinate to statically indeterminate.

\section{Undamped Critical Speed Map}

The impact of this extremely lightly loaded condition was then evaluated by a complete lateral rotordynamics analysis of alignment case 3 , which was chosen to be representative. The first task undertaken was the generation of the undamped critical speed map shown in Figure 9 so as to locate the machine's undamped critical speeds and provide an overview of the system's overall vibrational, behavior. This figure is a plot of the unit's undamped natural frequencies as a function of bearing stiffness, under the assumption that the stiffnesses at all bearings (except, of course, the lightly loaded blower float [inboard] bearing) are equal.

TABLE 2

Bearing Loading for Several Documented Alignment Cases

\begin{tabular}{lcccc}
\hline $\begin{array}{c}\text { Alignment case } \\
\text { number }\end{array}$ & $\begin{array}{c}\text { Motor fixed (outboard) } \\
\text { bearing load (lb) }\end{array}$ & $\begin{array}{c}\text { Motor float (inboard) } \\
\text { bearing load (lb) }\end{array}$ & $\begin{array}{c}\text { Blower float (inboard) } \\
\text { bearing load (lb) }\end{array}$ & $\begin{array}{c}\text { Blower fixed (outboard) } \\
\text { bearing load (lb) }\end{array}$ \\
\hline 1 & 1587 & 2272 & -2 & 1635 \\
2 & 1592 & 2257 & -4 & 1630 \\
3 & 1591 & 2259 & -2 & 1630 \\
4 & 1589 & 2262 & -1 & 1625 \\
5 & 1589 & 2264 & -4 & 1629 \\
6 & 1596 & 2237 & -8 & 1617 \\
7 & 1588 & 2267 & & 1630 \\
\hline
\end{tabular}




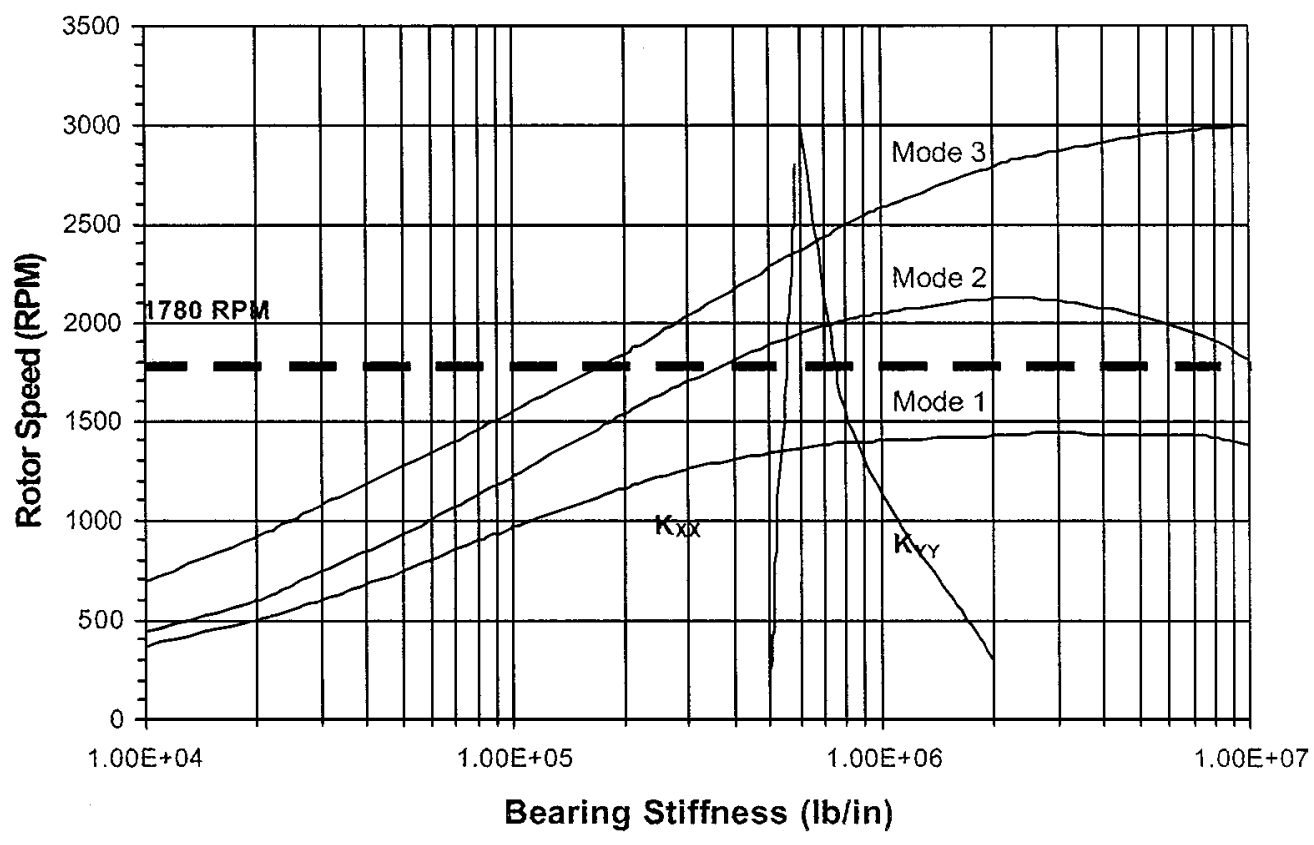

FIGURE 9

Undamped critical speed map, disk coupling.

Also plotted on the figure are the known horizontal $\left(\mathrm{k}_{\mathrm{xx}}\right)$ and vertical $\left(\mathrm{k}_{\mathrm{yy}}\right)$ stiffnesses versus speed characteristics for the blower fixed (outboard) bearing. The intersections between the natural frequency and the bearings' stiffness curves give approximate indications of the machine's undamped critical speeds. Inspection of the figure reveals that the anisotropy of the blower's plain cylindrical bearing results in each mode's having two critical speeds - one each for the horizontal and vertical directions.

Once the critical speed map was completed, its intersection points were used as starting points for finding the true undamped critical speeds. An iterative procedure was employed in which a critical speed was assumed and all bearing stiffnesses were set to their values at that speed. An undamped analysis was then run and the resulting natural frequency was compared to the assumed value. This process was continued until the assumed and resulting values were found to be in agreement.

Using this procedure, the undamped critical speeds were found to be as follows:

- First horizontal: $1357 \mathrm{rpm}$

- First vertical: $1407 \mathrm{rpm}$

- Second horizontal: $1870 \mathrm{rpm}$

- Second vertical: $2070 \mathrm{rpm}$

- Third horizontal: $2357 \mathrm{rpm}$

- Third vertical: $2453 \mathrm{rpm}$

\section{Undamped Mode Shapes}

The associated undamped mode shapes were developed. The shapes of the horizontal and vertical versions of each mode were found to be virtually identical, so only the horizontal mode shapes are presented. The ordinates represent the transverse deflections at a given axial location, normalized such that the largest deflection in the system equals 1.0.

Inspection of the mode shapes reveals that the first mode, at $1357 \mathrm{rpm}$, is the blower's first mode (Fig. 10). Likewise, it is observed that the second horizontal critical speed, at $1870 \mathrm{rpm}$, is the motor's first mode and that it is perilously close to the $1780 \mathrm{rpm}$ running speed (Fig. 11). Although this is a motor (not a blower) mode, it cannot be disregarded as a potential source of the observed problems because it has already been observed that high blower vibrations are almost always accompanied by high vibrations at the motor float (inboard) bearing.

\section{Damped Stability Analysis}

The machine was further evaluated by means of damped stability analyses. Such an analysis is run to evaluate the machine's susceptibility to rotordynamic instability phenomena, such as oil whirl and whip. No Bull Engineering evaluates rotor-bearing stability by performing a damped eigenvalue analysis, which determines the machine's damped natural frequencies and associated log decrements.

The $\log$ decrement is a measure of the stability of a given vibratory mode when the machine is exposed to minute perturbations. A negative log decrement indicates that such perturbations will be amplified and that the mode is, thus, unstable. Such instability usually manifests itself in large self-excited subsynchronous vibrations. Conversely, a positive value for the log decrement indicates that a mode is stable and that small perturbations will be damped out. Furthermore, as the log decrement's magnitude increases, the stability margin also increases. Based on our extensive experience, the authors generally recommend 


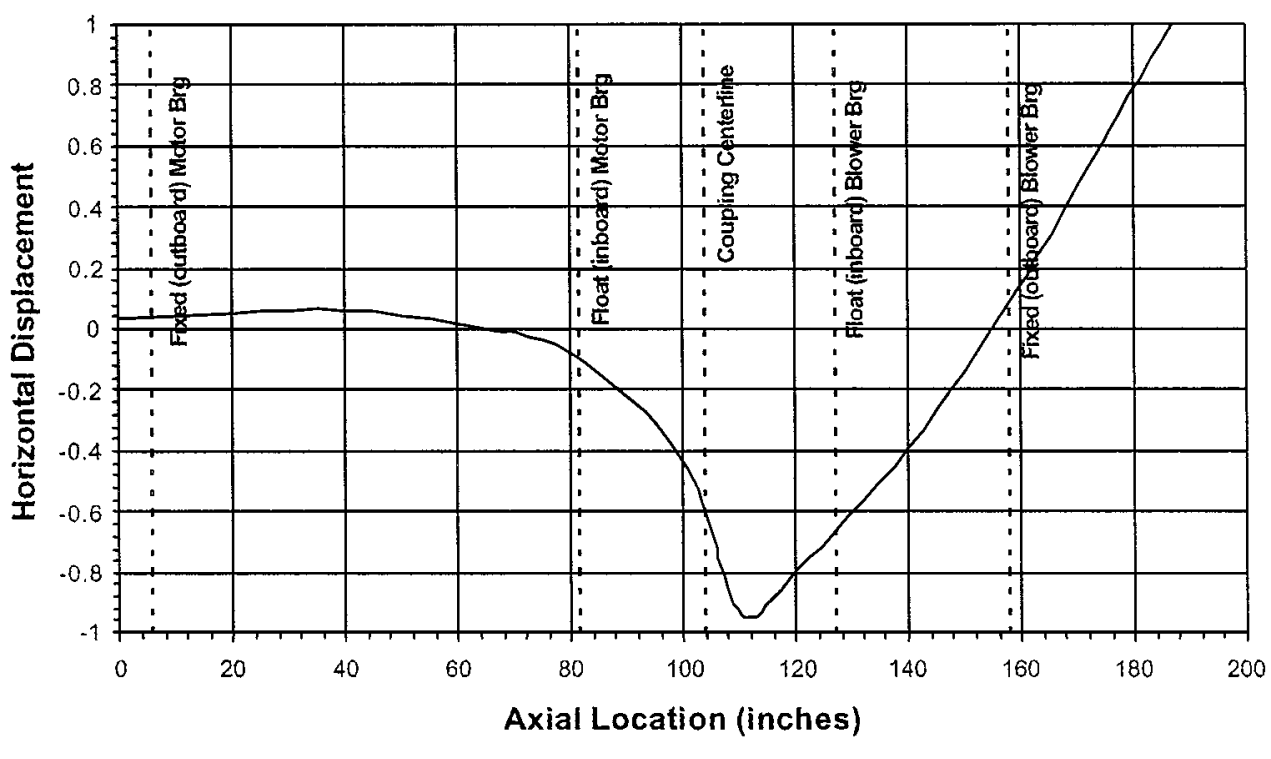

FIGURE 10

First horizontal mode (1357 rpm), disk coupling.

that machines be designed so that all easily excited modes exhibit a log decrement of +0.30 or greater. The results obtained from the stability analysis are shown in Table 3 .

No mechanisms are capable of exciting a backwards whirling mode. Thus, all backwards whirl modes were dismissed from further consideration.

Therefore, we were left with only two modes to considerthe fourth and the ninth. Because the ninth mode occurs at a speed $(2835 \mathrm{rpm})$ that is above the $1780 \mathrm{rpm}$ running speed and because rotordynamic instability is inherently a subsynchronous phenomenon, this mode was quickly eliminated. That left the fourth mode, $1527 \mathrm{rpm}$, which corresponds to the blower's first undamped mode.
Although the fourth mode's log decrement of +0.241 indicates that this mode is stable, the magnitude of the log decrement is slightly less that the +0.30 value, which is normally used as a threshold. However, it should be remembered that for machines like this one, in which the primary source of rotordynamic instability is plain cylindrical journal bearings, the resulting mode of instability is half-speed whirl, in accordance with the average circumferential velocity that the oil attains within the bearings. Accordingly, instability can occur only if the natural frequency of interest is less than one-half of the running speed. Because the fourth mode's natural frequency of $1527 \mathrm{rpm}$ is significantly greater than one-half of this unit's $1780 \mathrm{rpm}$ running speed, the destabilzing mechanisms in the cylindrical journal bearings are

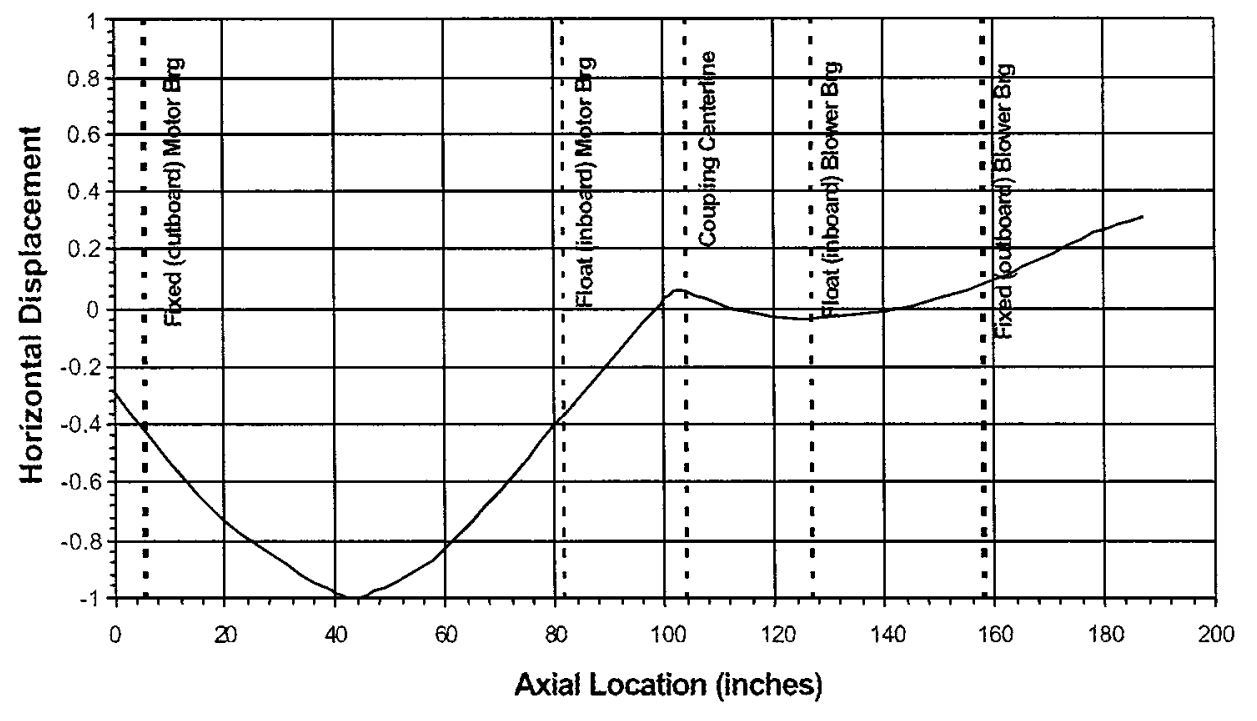

FIGURE 11

Second horizontal mode (1870 rpm), disk coupling. 
TABLE 3

Results of Damped Stability Analysis

\begin{tabular}{lcl}
\hline $\begin{array}{l}\text { Damped natural } \\
\text { frequency (rpm) }\end{array}$ & Log decrement & Whirl direction \\
\hline 573.6 & +0.332 & Backwards \\
1249.5 & +3.036 & Backwards \\
1289.3 & +4.854 & Backwards \\
1526.6 & +0.241 & Forwards \\
1674.2 & +5.897 & Backwards \\
1694.2 & +1.065 & Backwards \\
2066.8 & +0.812 & Backwards \\
2424.5 & +0.281 & Backwards \\
2835.2 & +0.488 & Forwards \\
\hline
\end{tabular}

not capable of exciting this mode. Accordingly, this mode was also determined to be a nonproblem.

It was, therefore, concluded that subsynchronous whirling due to rotordynamic instability was not the cause of this blower's observed vibration problems. This was not a great surprise because most of the measured data have indicated the high vibration frequencies to be synchronous, not subsynchronous. This suggests that the problem is more likely to involve strong response to unbalance, which was subsequently evaluated using an unbalance response analysis.

\section{Unbalance Response Analysis}

An unbalance response analysis consists of the determination of the synchronous response of the system to strategically placed unbalancing forces. The shaft's movement (vibration amplitude) at strategic locations on the rotor is calculated and plotted as a function of speed on a Bode plot. These displacements are of great interest in locations such as bearings, shaft seals, and im- pellers, where they can be compared to the minimum operating clearances so as to evaluate the possibility that rubs will occur. Of course, the shaft displacements at the bearings can be compared to the measured values taken from the field so as to evaluate the analysis' effectiveness in predicting real-world behavior.

The blower wheel's unbalance was taken to be $10.9 \mathrm{oz}-$ in, which corresponds to a G2.5 level of precision AMCA/ ANSI-). Use of this unbalance value allowed for a direct comparison of the comprehensive model's results and those from previous rotordynamic analyses performed on the blower shaft alone (see Fig. 6).

The blower and motor coupling-half unbalances were calculated to be 6.822 and $7.00 \mathrm{oz}$-in, respectively $(40 \mathrm{~W} / \mathrm{N}$ unbalance, per API 671). For the cases in which these were relevant, they were applied at the coupling-half centers of gravity, as defined by the coupling manufacturer.

The motor unbalance was calculated as $7.533 \mathrm{oz}$-in $(4 \mathrm{~W} / \mathrm{N})$, applied to the model at the centerline of the motor core.

The case 1 run was simply the one that had been run previously, in the prior rotordynamics analyses. That is, the $10.9 \mathrm{oz}-\mathrm{in}$ unbalance was applied to the blower wheel and the response was calculated. It should be recalled that in the previous analysis, the running speed amplitude at the blower float (inboard) bearing was calculated to be only 1.3 mils, pp. This indicated a major disagreement between the analysis and reality, in that the observed amplitudes at this bearing just prior to a failure or shutdown were more on the order of 4 to 5 mils pp.

The results of the new analysis for the case in which blower wheel unbalance was applied by itself are presented in Figure 12. Examination of the figure reveals that the float (inboard) blower bearing experiences a relatively sharp peak at $1500 \mathrm{rpm}$. The fact that the peak vibration at the blower float (inboard) bearing is much higher than that at the blower fixed (outboard) bearing is in agreement with the undamped mode shapes.

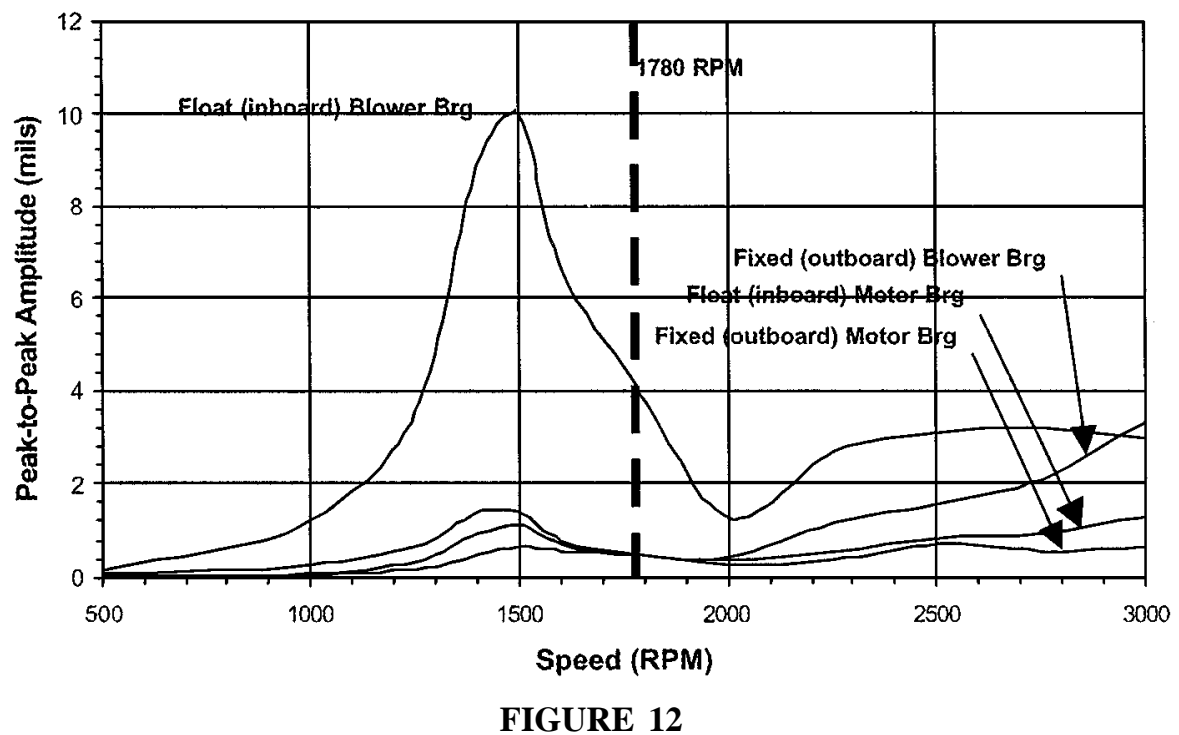

Unbalance response, disk coupling: case 1. 


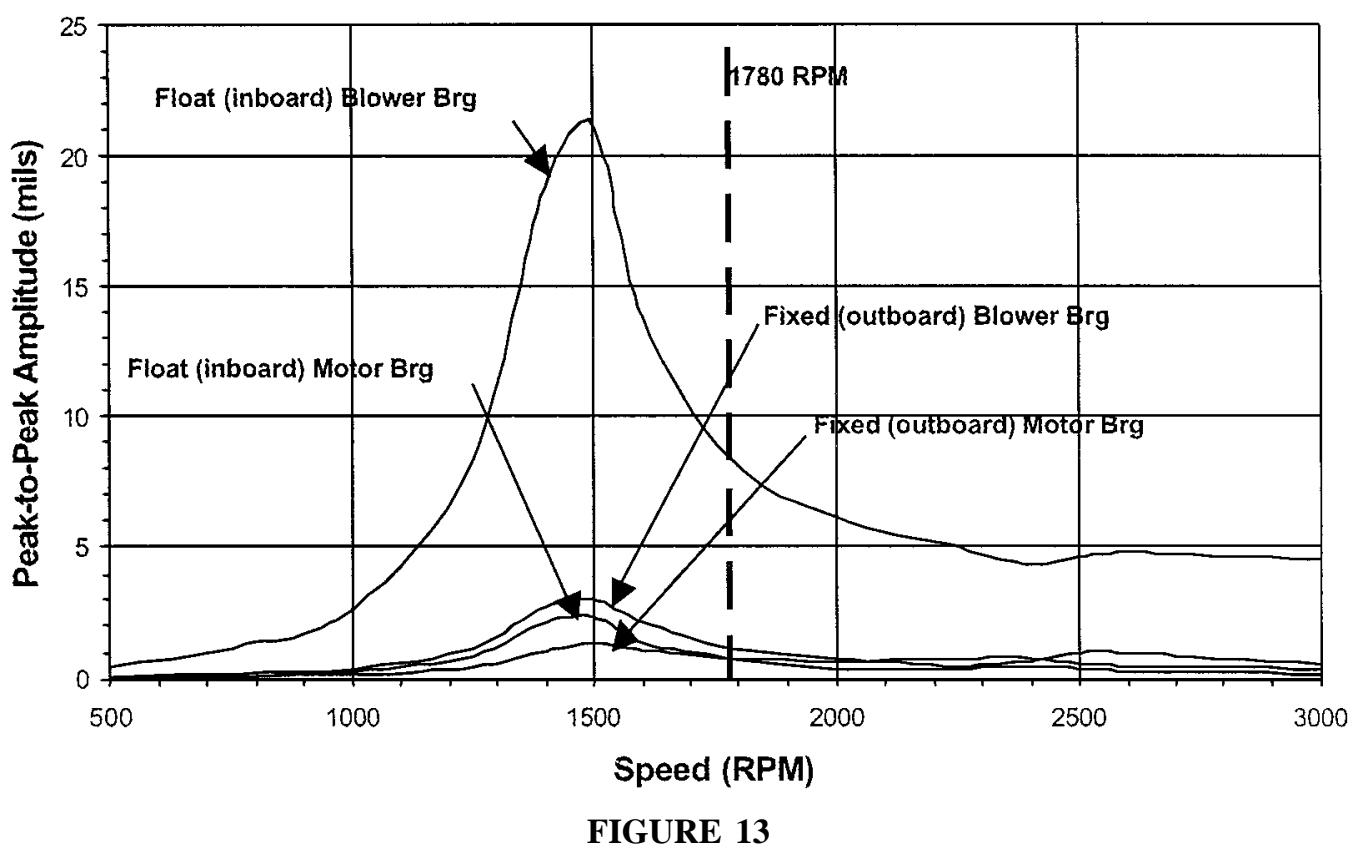

Unbalance response, disk coupling: case 2. The coupling unbalance is applied 180 degrees out of phase with blower wheel.

The blower float (inboard) bearing's displacement at the 1780-rpm running speed is calculated to be 4.1 mils, pp, and is in much better agreement with observations than were the previous rotordynamic analyses' results of 1.3 mils, pp.

The unbalance distribution selected for case 2 was also chosen with the aim of exciting the blower's first mode. Examination of the undamped mode shapes in this mode reveals that not only is this mode sensitive to blower wheel unbalance; it should also respond to coupling unbalance. Accordingly, in case 2, the $10.9 \mathrm{oz}$-in blower wheel unbalance was applied out of phase with the maximum coupling unbalances. The results, presented in Figure 13, reveal that coupling unbalance is, indeed, significant since adding it causes the running speed vibration at the blower float (inboard) bearing to increase from 4.1 to 8.4 mils, pp. It is easily seen that the results of this case easily explain the observed high vibrations and accompanying bearing failures.

Unbalancing the motor's rotor had little effect on the blower float (inboard) vibration, so it was concluded that the mode that had been responsible for the observed problems was the blower's first mode at $1500 \mathrm{rpm}$.

As a result of performing the comprehensive model's unbalance response analysis, we were able to arrive at the following conclusions:

1. We had finally succeeded in coming up with a model and analysis that explained the observed vibration problems.

2. The calculated vibration amplitudes at the blower float (inboard) bearing in cases 1 and 2-4.1 and 8.4 mils, peak to peak, respectively - were in good agreement with observed values.

3. The analysis' prediction that the blower float (inboard) bearing's amplitude was much greater than that at the blower fixed (outboard) bearing is also in complete agreement with observation.

4. The analysis' prediction that the peak response at the blower float (inboard) bearing occurred at a speed ( $1500 \mathrm{rpm}$ ) below the running speed of $1780 \mathrm{rpm}$ was also in agreement with observation. This was at least a partial explanation for the unit's bizarre behavior in which its vibration increased as its speed decreased during coast-downs.

5. Accordingly, the observed vibration problem was concluded to be a synchronous problem that was caused by the proximity of the $1780 \mathrm{rpm}$ running speed to the blower's first critical speed at $1500 \mathrm{rpm}$. The observed problem was entirely unrelated to subsynchronous instability.

6. The observed high vibrations at the blower float (inboard) bearing were being driven by a combination of blower wheel and coupling unbalances.

7. The primary reason for the high vibrations at the blower float (inboard) bearing was the extremely light load (as little as $1 \mathrm{lb}$ ) that this bearing carried (partially as a result of the disk coupling's extreme angular stiffness). The resulting extremely low values for this bearing's stiffness and damping allowed the vibrations at the bearing location to be high because there were virtually no fluid forces there to restrict them.

8. There was nothing wrong with the previous rotordynamic analyses that predicted relatively low vibration amplitudes at the blower float (inboard) bearing. They were most likely correct for the portion of the system that they were modeling. However, the only way that the extreme unloading that was occurring at the blower float (inboard) bearing could be predicted was to employ a comprehensive model that included the motor, coupling, and blower, as was done herein. 


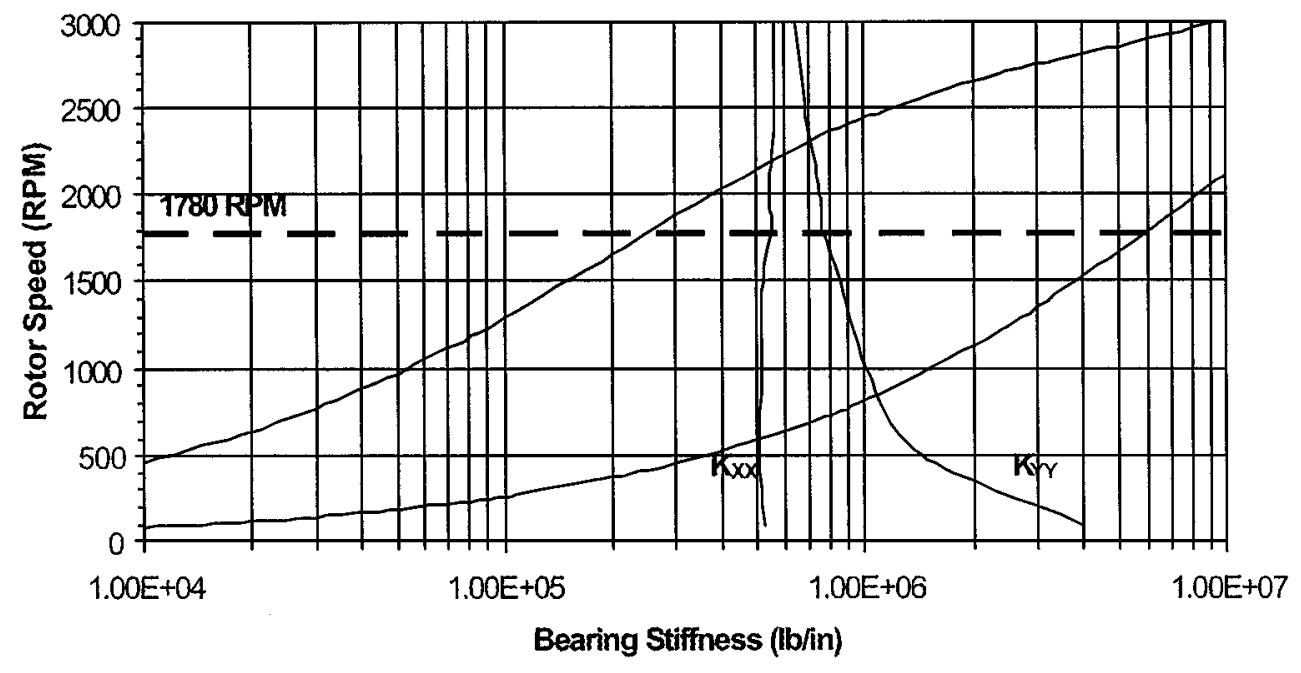

FIGURE 14

Undamped critical speed map, gear coupling.

9. Because the relatively extreme angular stiffness of the original disk coupling played a large role in the unloading of the blower float (inboard) bearing, the proposed change to the much more flexible gear coupling was likely to alleviate the vibration problem.

10. Also, because the current plain cylindrical bearing employed in the blower float (inboard) location was extremely vulnerable to the lightly loaded condition, a change to a tilting-pad design in that location was likely to alleviate or eliminate the vibration problem.

\section{Lateral Analysis Using Gear Coupling}

Another rotordynamics analysis was run using a gear coupling (i.e., the same gear coupling that was put into operation in the field during the analysis failure). The purpose of performing this analysis was twofold: (1) to verify that the coupling change would significantly alleviate the current vibration problem; and (2) to ensure that the coupling change did not introduce any new rotor dynamic problems into the system.

Because the gear coupling was assumed to transmit no moment between the blower and motor shafts, the comprehensive approach that was used with the disk coupling was set aside and the blower and motor were, once again, treated as two independent systems, from a rotordynamics standpoint. The comprehensive rotordynamic model was, thus, altered so that it represented the blower shaft only.

Once the new rotordynamic model was generated, it was again employed in a static loading analysis of the bearing. However, because the system then had only two supports, the analysis changed from the previous statically indeterminate beam analysis, which is fairly complex, to a much simpler statically determinate beam analysis. Using this analysis, the load on the blower float (inboard) bearing was calculated to be $46 \mathrm{lbs}$ - still a light load, but a significant improvement over the 2-lb load employed in the disk coupling analysis.
Using the new model and loadings, a complete rotordynamics analysis was performed for the new machine. Using the same methodology described previously, the undamped critical speed map in Figure 14 was generated. It can be seen once again that the anisotropy of the blower's plain cylindrical bearings yields both horizontal and vertical critical speeds for each vibratory mode. Using the iterative procedure described previously, the undamped critical speeds were found to be as follows:

- First horizontal: $613 \mathrm{rpm}$

- First vertical: $663 \mathrm{rpm}$

- Second horizontal: $2187 \mathrm{rpm}$

- Second vertical: $2356 \mathrm{rpm}$

The associated undamped mode shapes are presented in Figures 15 and 16. Once again, the vertical mode shapes are omitted because they are redundant. In these plots, the left-hand side of the plot represents the coupling end of the blower shaft, and the right-hand side corresponds to the blower wheel end.

Inspection of the mode shapes reveals that the first mode, at $613 \mathrm{rpm}$, is a conical mode in which the blower shaft acts as a rigid body that is pivoted at the fixed (outboard) bearing. The coupling hub and blower wheel move in opposition to each other while the float (inboard) bearing provides virtually no restraint as a result of its lightly loaded condition. The second mode, at $2187 \mathrm{rpm}$, is seen to represent the shaft's first bending mode.

An item of interest is how the switch from the disk coupling to the gear coupling resulted in the critical speed of the blower's conical mode being significantly reduced (to between 1357 and $613 \mathrm{rpm}$ ). Comparison of Figures 10 and 16 reveals that the blower shaft's behavior is virtually identical in both modes. However, the angular rigidity of the disk coupling provides resistance to motion, and that is absent in the gear coupling system. This increased resistance results in a raising of the 


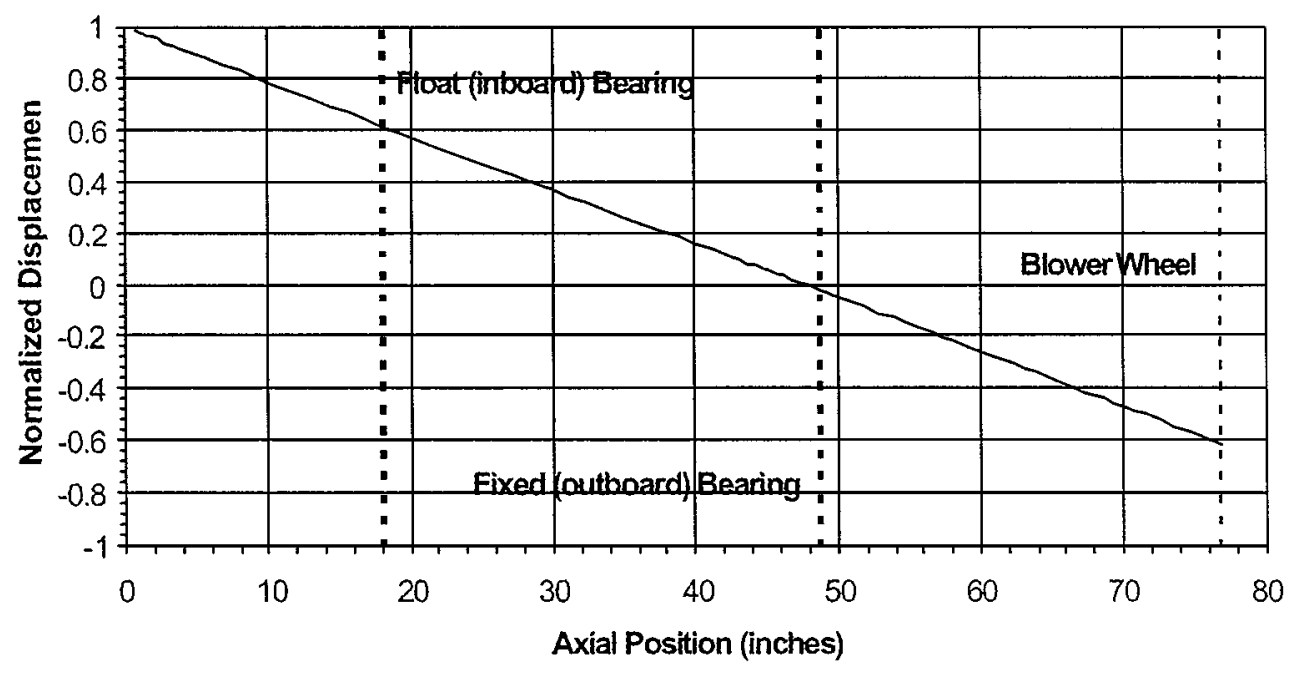

FIGURE 15

First horizontal mode (613 rpm), gear coupling.

machine's first critical speed, which is generally beneficial. Thus, although employment of the gear coupling acts to partially alleviate the lightly loaded bearing problem, it is seen that it also has a potentially adverse impact on the machine. It should be noted that the initial disk coupling analysis, which ignored the angular rigidity of the coupling, also found the first critical speed to be in the vicinity of $750 \mathrm{rpm}$ (see Fig. 4).

Once the undamped analysis was complete, the system's synchronous response behavior was evaluated via an unbalance response analysis. The unbalance magnitudes were determined in the same manner as that employed for the disk coupling machine; that is, the blower wheel's unbalance was set at $10.9 \mathrm{oz}$-in and the gear coupling half's unbalance was calculated from the $40 \mathrm{~W} / \mathrm{N}$ relation.

Once the unbalance magnitudes were known, they were applied to the rotordynamic model in various combinations in an attempt to excite the first two modes. The case 1 run was simply the one that had been run previously in the prior rotordynamics analyses. That is, the $10.9 \mathrm{oz}$-in unbalance was applied to the blower wheel and the response was calculated; the results are given in Figure 17. In case 2 (Fig. 18) blower wheel and coupling unbalance were applied out of phase in an attempt to excite the first mode. Likewise, Figure 19 provides the results for case 3, where the coupling and blower wheel unbalances were applied in-phase to try and excite the second mode.

Examination of the three figures reveals that there are fairly small peaks in the vicinity of $1000 \mathrm{rpm}$, which corresponds to the first mode. There also are fairly well-damped peaks in the vicinity of $2500 \mathrm{rpm}$, representing excitation of the second mode. The fact that this mode is relatively well damped is not surprising because the shape of its mode exhibits significant amplitude at the fixed (outboard) bearing, indicating that its considerable

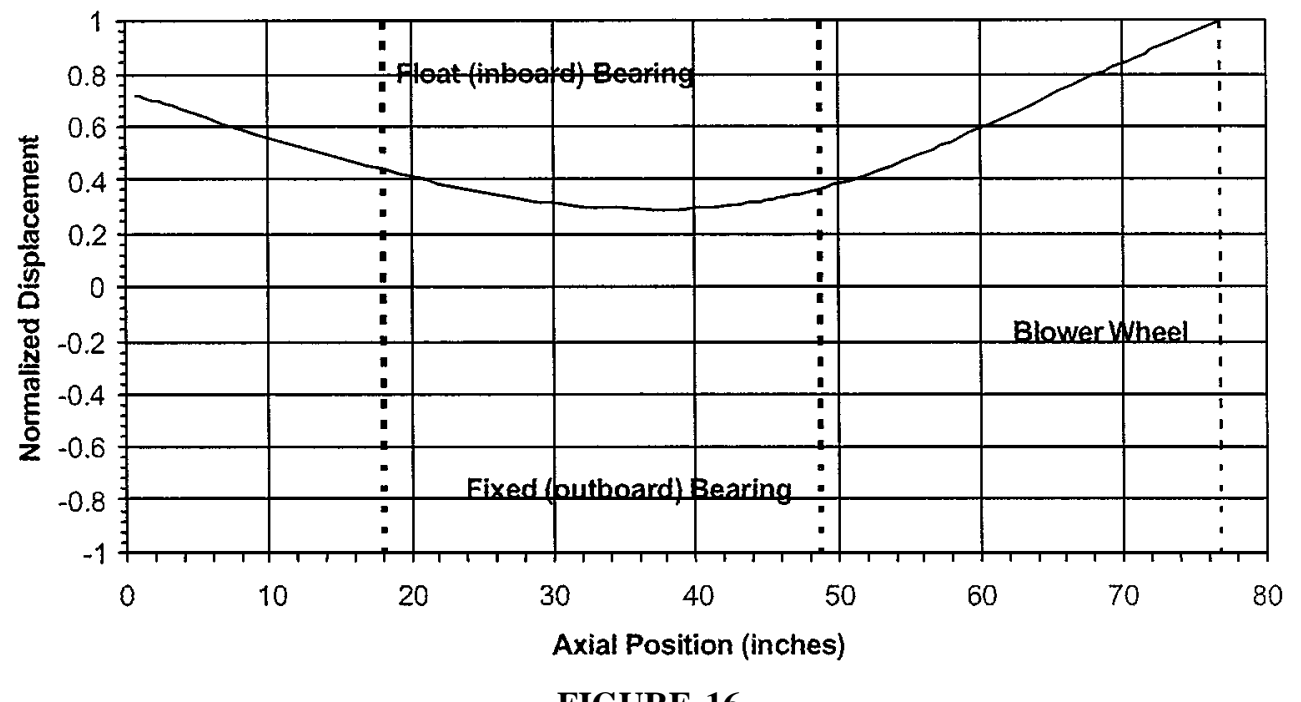

Second horizontal mode (2187 rpm), gear coupling. 


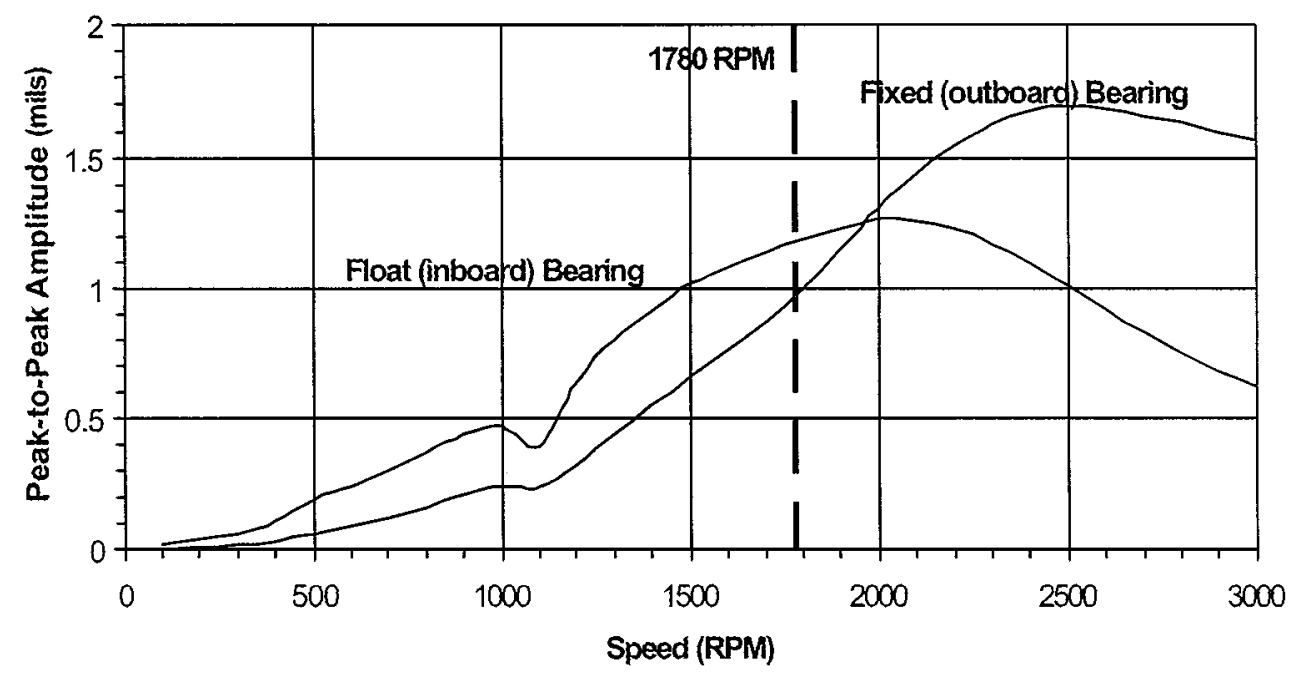

FIGURE 17

Unbalance response, gear coupling: case 1 .

damping should be relatively effective in suppressing this mode (the amplitude at the float [inboard] bearing is much less meaningful because it provides very little damping due to its lightly loaded condition). The vibration amplitudes at the two bearings at running speed are contained in Table 4.

Thus, it is clear that changing to the gear coupling resulted in a significant reduction in the synchronous vibrations at the float (inboard) bearing, which were found to range from 4.1 to 8.4 mils, pp, with the disk coupling. This confirms the empirical observation that, in general, the blower's vibratory behavior was better with the gear coupling than it was with the disk coupling.

Once the unbalance response was complete, a stability analysis was run to ensure that the gear coupling had not introduced any instability problems into the system. Using the same proce- dure as that used for the previous machine, the stability analysis results were found to be as detailed in Table 5.

These results were eye-opening because of the presence of the highly unstable mode at $1031 \mathrm{rpm}$. Examination of this mode's deflected shape (not shown) revealed that this was merely the first conical mode. The reason for the instability can be understood by inspection of the mode shape found in Figure 15. The primary source of damping in this machine, the fixed (outboard) bearing, had very little impact on this mode because there was very little motion there. The only source of damping in this mode was the float (inboard) bearing but, as has been previously noted, it provides very little damping because of its lightly loaded condition. This absence of damping leads to instability. It should be noted that many overhung machines are plagued by unstable

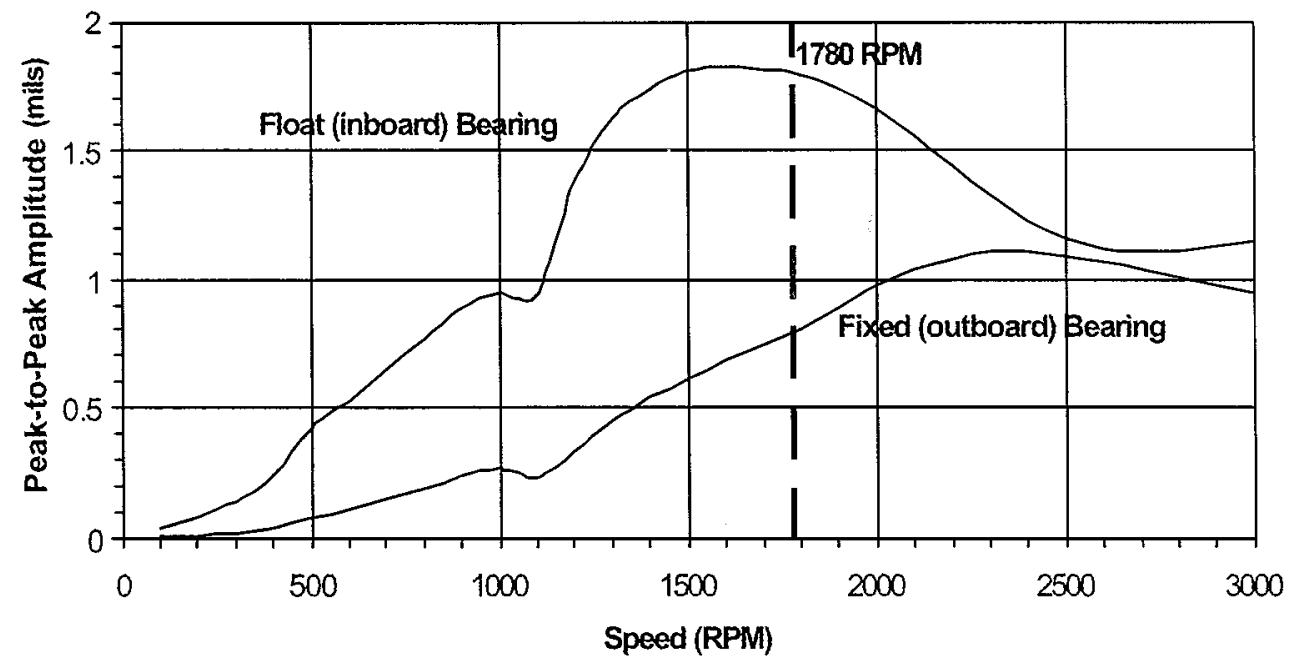

FIGURE 18

Unbalance response, gear coupling: case 2. The coupling unbalance was applied 180 degrees out of phase with the blower wheel. 
TABLE 4

Vibration Amplitudes at the Blower's, Bearings at Running Speed

\begin{tabular}{lcc}
\hline & $\begin{array}{c}\text { Float (inboard) bearing } \\
\text { (mils, peak to peak) }\end{array}$ & $\begin{array}{c}\text { Fixed (outboard) bearing } \\
\text { (mils, peak to peak) }\end{array}$ \\
\hline Case 1 & 1.2 & 1.0 \\
Case 2 & 1.8 & 0.8 \\
Case 3 & 0.9 & 1.3 \\
\hline
\end{tabular}

conical modes because their float (inboard) bearings are lightly loaded as these are.

The reason the machine with the gear coupling is unstable but the one with the disk coupling isn't is the same reason previously advanced for greatly reducing the blower's first critical speed - that is, the angular rigidity of the disk coupling introduces additional resistance to the system and brings the damping from the motor's two bearings into play.

Although the unstable mode's $1031 \mathrm{rpm}$ natural frequency is greater than one-half of the $1780 \mathrm{rpm}$ running speed (58\% to be exact), its not far enough above it to suit us, especially considering the large magnitude of its log decrement. Thus, although synchronous whirling is believed to be responsible for the bearing failures that occurred with the disk coupling installed, its quite possible that the one failure that occurred with the gear coupling was due to subsynchronous whirling. Thus, although the gear coupling has been observed to generally improve the machine's vibratory behavior, we don't view it as a long-term solution to the problem.

\section{Lateral Analysis Using Gear Coupling and Tilting-Pad Blower Bearings}

Because the original analysis also indicated that a major contributor to the observed vibration problems was the original plain cylindrical bearings' susceptibility to a lightly loaded condition, the switch to a tilting-pad design was also investigated. The logic behind this was that since a tilting-pad bearing employing both geometric preload and offset pivots will generate significant stiffness and damping even under no load, the light loading on the blower float (inboard) bearing would be a much smaller problem with such bearings. Accordingly, the analysis was repeated again using tilting-pad bearings instead of the original

TABLE 5

Stability Analysis Using Gear Coupling

\begin{tabular}{ccc}
\hline $\begin{array}{l}\text { Damped natural } \\
\text { frequency }(\mathrm{rpm})\end{array}$ & Log decrement & Whirl direction \\
\hline 827.1 & +1.294 & Forwards \\
1031.0 & -1.059 & Forwards \\
1347.9 & +2.359 & Forwards \\
2537.3 & +1.402 & Forwards \\
\hline
\end{tabular}

plain-sleeve bearings. We anticipated that this would improve the unit's vibration behavior without introducing new problems.

The first task undertaken was the design of the tilting-pad bearings. Based on past successful experience, a four-pad design with the load oriented midway between pivots was selected. One of the many benefits of using this configuration is that it makes the bearing completely isotropic - the horizontal and vertical stiffness and damping coefficients are identical, regardless of load. Because of the light loading at the float (inboard) bearing, a relatively high geometric preload (0.50) and a high (60\%) pivot offset were selected.

This unit still employed the gear coupling described in the last section, so the blower's rotordynamic model and the bearing loadings were not changed. Accordingly, the float (inboard) bearing was still relatively lightly loaded, with a load of $46 \mathrm{lbs}$. However, the value of using the tilting-pad design was illustrated when the float (inboard) bearing's horizontal stiffness and damping coefficients were calculated to be $609,000 \mathrm{lb} / \mathrm{in}$ and $3089 \mathrm{lb}-\mathrm{sec} / \mathrm{in}$, respectively. For the sake of comparison, the plain cylindrical bearing under the same 46-lb load generated values of 13,700 lb/in and $642 \mathrm{lb}$-sec/in for those same quantities. Although the increases in the fixed (outboard) bearing's coefficients were less dramatic, they were also significant.

The rotordynamics analysis of the unit incorporating the tilting-pad bearings was begun with the generation of the critical speed map shown in Figure 20. The symmetrical characteristics of these tilting-pad bearings resulted in the horizontal and vertical stiffnesses' ( $\mathrm{k}_{\mathrm{XX}}$ and $\mathrm{k}_{\mathrm{YY}}$, respectively) being identical and consequently, each vibration mode had only one critical speed. This machine's first two undamped critical speeds were, thus, found to occur at 2109 and $3809 \mathrm{rpm}$. Because all criticals are located above the $1780 \mathrm{rpm}$ running speed, the benefits provided by the tilting-pad bearings were already making themselves apparent.

The shapes of the associated undamped modes are presented in Figures 21 and 22. Inspection of the mode shapes reveals that these modes look very much like the first two modes associated with a conventional overhung machine. That is, the first mode exhibits maximum amplitude at the overhung wheel, whereas in the second, the wheel is fairly dormant.

Once the undamped analysis was complete, the system's synchronous response behavior was again evaluated via an unbalance response analysis. The blower and coupling hub's unbalance magnitudes were identical to those used for the machine employing the gear coupling-cylindrical bearings combination. Again, the first case run was the one in which the sole unbalance applied was 10.9 oz-in at the blower wheel. Because Figure 21 suggests that adding the coupling's unbalance out of phase with that of the blower wheel might increase the response, this combination was run as case 2 . The results of these two cases are provided in Figures 23 and 24.

Examination of these figures reveals that in both cases, the peak vibration, corresponding to the first mode, occurs at about $2400 \mathrm{rpm}$. Furthermore, the additional coupling unbalance 


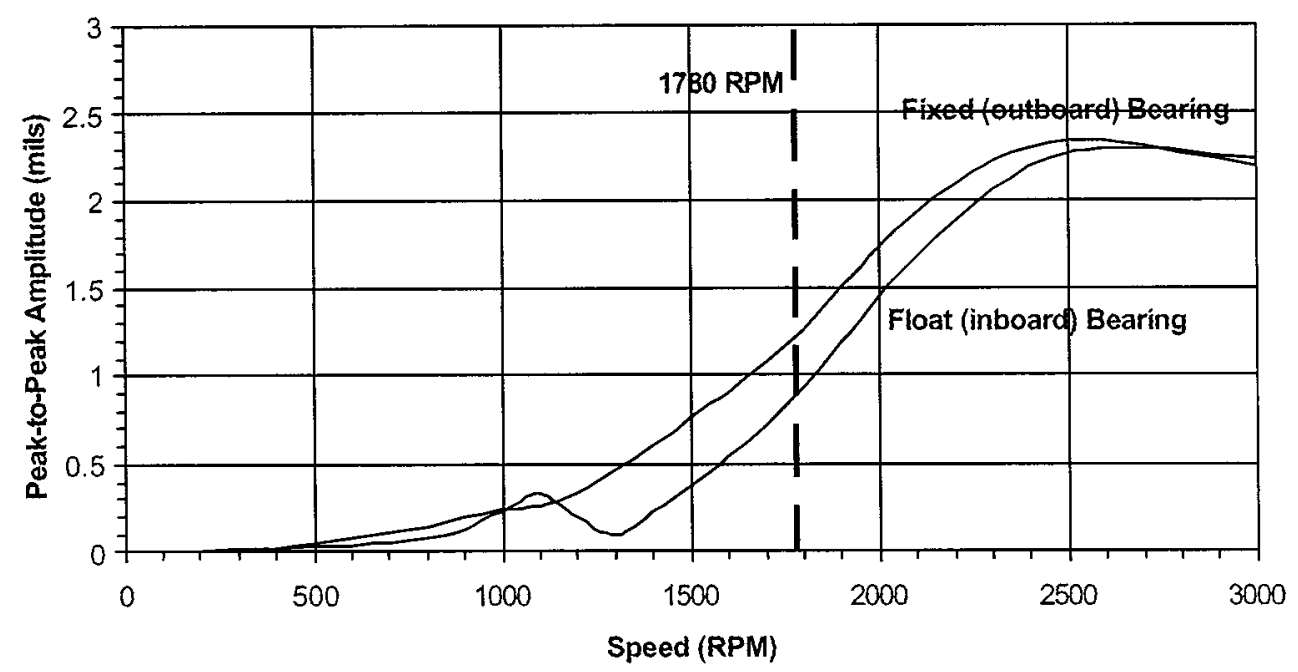

FIGURE 19

Unbalance response, gear coupling: case 3. The coupling unbalance was applied in phase with the blower wheel.

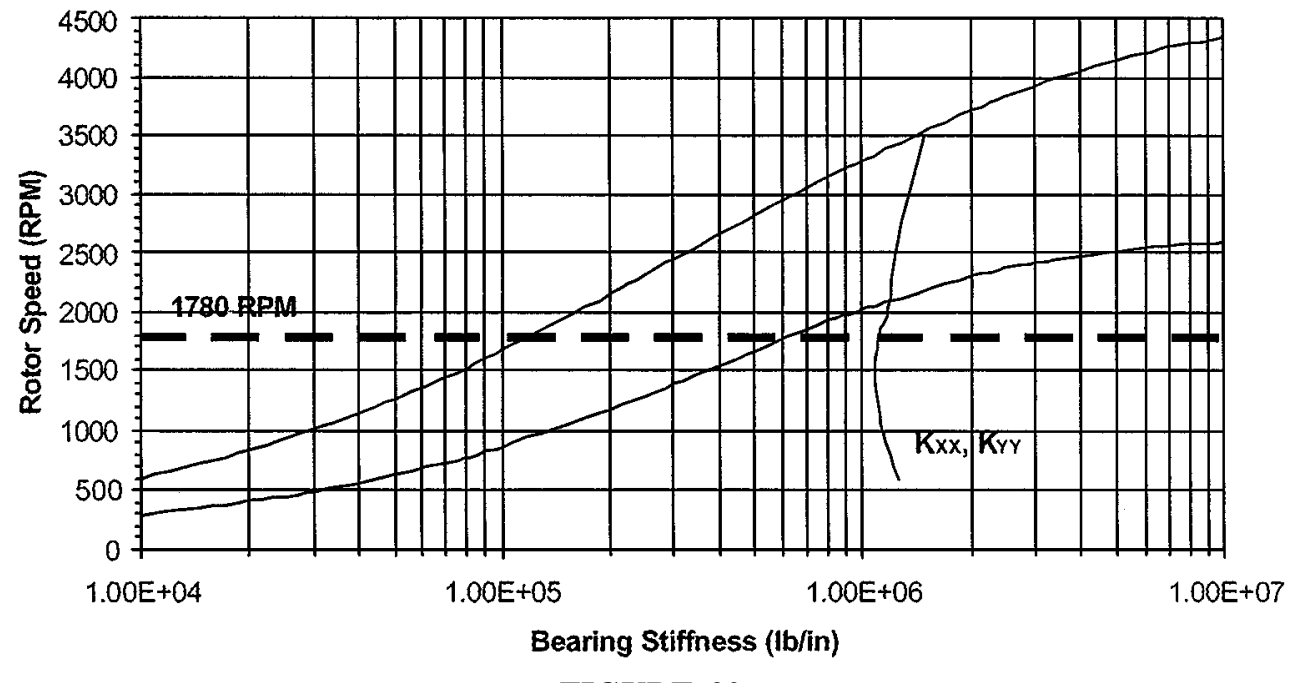

FIGURE 20

A critical speed map using a tilting-pad bearing.

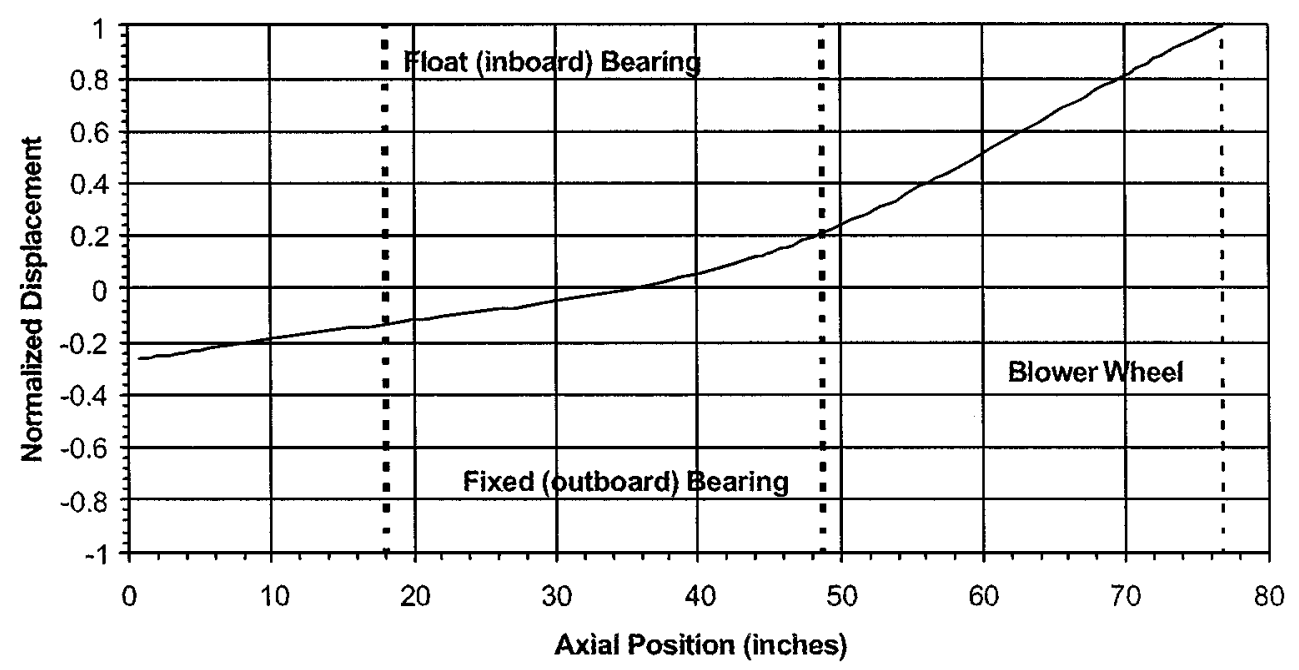

FIGURE 21

The tilting pad bearing, first mode (2109 rpm). 


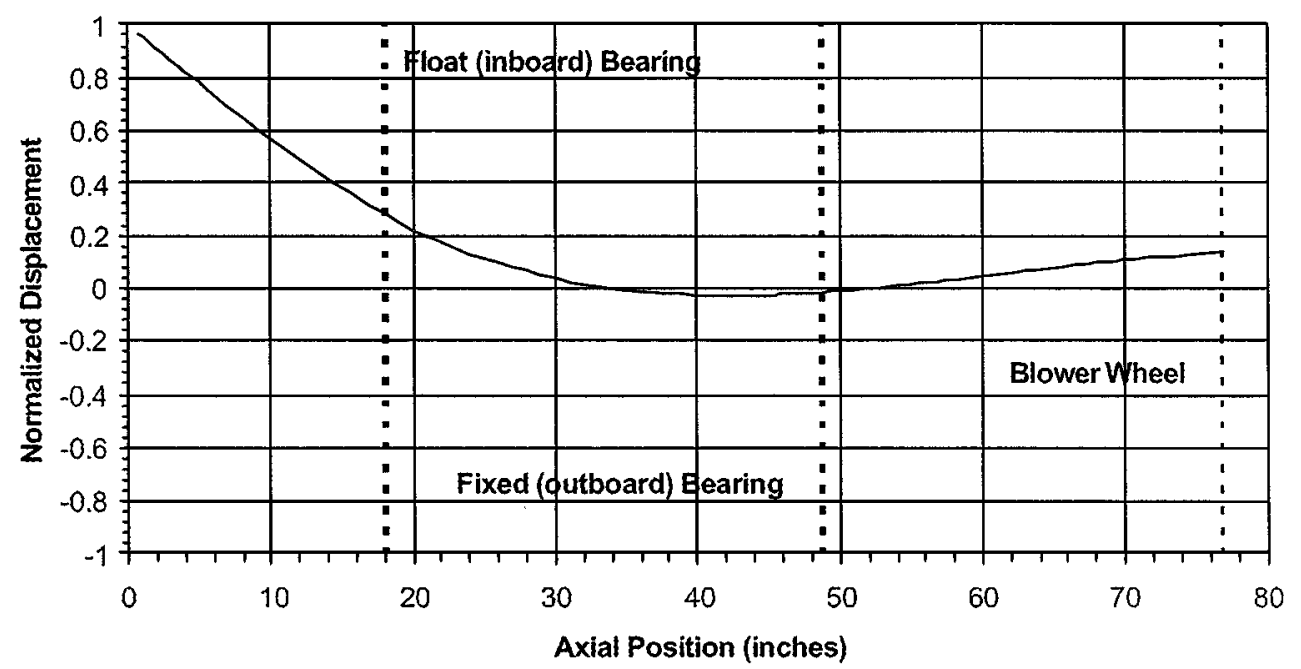

FIGURE 22

The tilting pad bearing, second mode (3809 rpm).

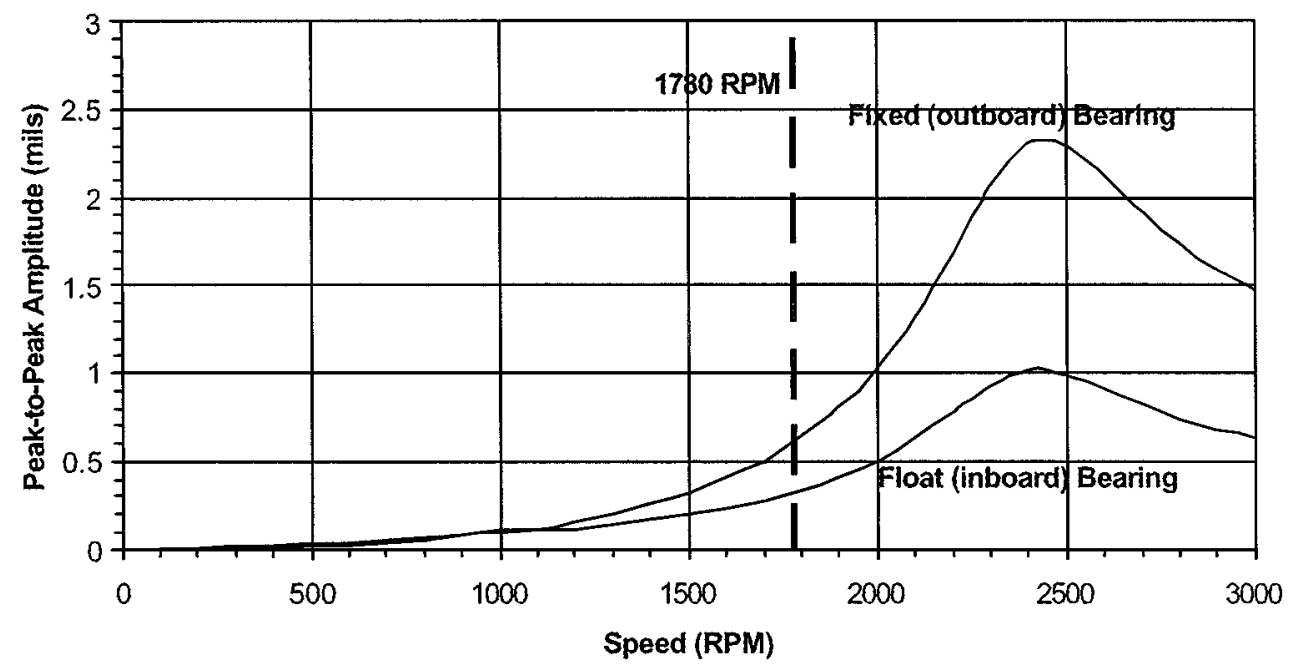

FIGURE 23

Unbalance response, tilting-pad bearing: case 1 .

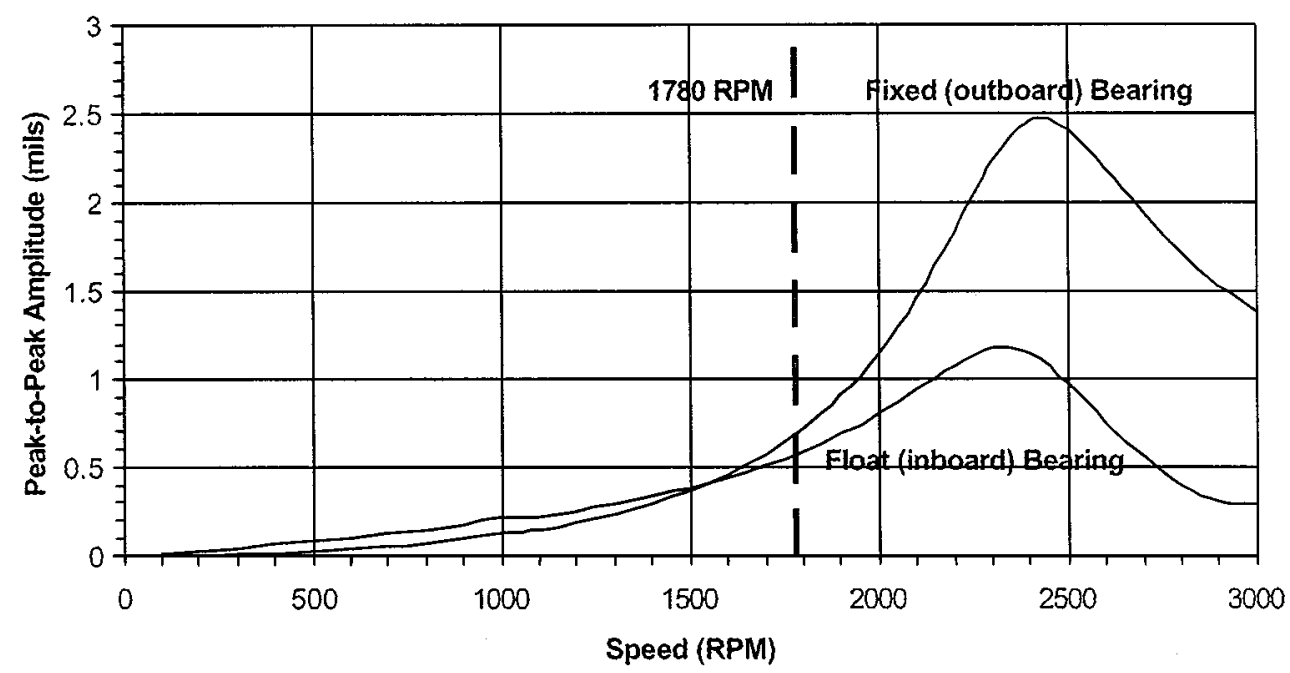

FIGURE 24

Unbalance response, tilting-pad bearing: case 2. The coupling unbalance was applied 180 degrees out of phase with the blower wheel. 
TABLE 6

Running-Speed Vibration Amplitudes at Blower Bearings

\begin{tabular}{lcc}
\hline & $\begin{array}{c}\text { Float (inboard) bearing } \\
\text { (mils, peak to peak) }\end{array}$ & $\begin{array}{c}\text { Fixed (outboard) bearing } \\
\text { (mils, peak to peak) }\end{array}$ \\
\hline Case 1 & 0.34 & 0.64 \\
Case 2 & 0.59 & 0.72 \\
\hline
\end{tabular}

employed in case 2 results in a very small change in the peak amplitudes. This suggests that the first mode is much more sensitive to blower wheel unbalance than to coupling unbalance, a conclusion that could have been made by merely looking at the mode shape. Additionally, the peaks at both bearings are broad rather than sharp, indicating that the tilting-pad bearings are doing a good job of damping this mode. The running speed vibration amplitudes at the two bearings were found to be as shown in Table 6.

Thus, it is seen that changing from plain cylindrical to tiltingpad bearings meant that the running speed vibrations at both bearings were less than one mils, pp. This was the best synchronous-response performance of the three configurations analyzed and was a large improvement over the original machine (whose vibrations at the float (inboard) bearing could be as large as 8 mils, pp). Accordingly, the change to tilting-pad bearings, along with the change to a gear coupling, was determined to be sufficient to resolve the synchronous-vibration problem that led to the observed bearing failures.

Subsequent to the unbalance-response analysis, the tiltingpad bearing machine was subjected to a stability analysis. The results are shown in Table 7.

Again discarding the backward whirl mode for the reasons previously discussed, it was seen that both remaining modes are higly stable, in addition to being above the $1780 \mathrm{rpm}$ running speed.

This machine is highly stable, which was to be expected because tilting-pad bearings are renowned for their stability. Accordingly, it was concluded that the change to the gear coupling and to tilting-pad bearings would solve the vibration problem and provide a much more smoothly running, more stable machine.

\section{Torsional Analysis with Metal Disk Coupling}

In addition to the lateral rotordynamics analysis described previously, the original machine, employing the metal disk cou-

TABLE 7

Results of Stability Analysis: Tilting-Pad Bearings

\begin{tabular}{ccc}
\hline $\begin{array}{l}\text { Damped natural } \\
\text { frequency (rpm) }\end{array}$ & Log decrement & Whirl direction \\
\hline 828.5 & +0.209 & Backwards \\
2209.0 & +0.582 & Forwards \\
3901.0 & +1.145 & Forwards \\
\hline
\end{tabular}

pling, was also subjected to a torsional vibration analysis. A lumped perimeter model was generated, the undamped torsional natural frequencies and mode shapes were calculated, and the natural frequencies and potential excitation sources were plotted on a Campbell diagram to identify the system's torsional critical speeds. Since these critical speeds were all found to be sufficiently removed from the unit's $1780 \mathrm{rpm}$ operating speed, it was concluded that the observed vibration problem did not have torsional origins. This analysis was rather ordinary, so its details are omitted.

\section{Torsional Analysis with Gear Coupling}

Of course, it was necessary to rerun the torsional vibration analysis with the new coupling because it represented a change in the torsional stiffness of the coupling and therefore, the system's torsional characteristics. This analysis revealed that replacing the disk coupling with the gear coupling would have no adverse impact from the standpoint of torsional vibration. It should be noted that since the change from cylindrical to tilting-pad bearings had no impact on the blower's torsional characteristics, a separate analysis of the system incorporating tilting-pad bearings was not needed.

\section{RESULTS \\ Coupling Change}

The change from the metal disk coupling to the gear coupling resulted in lower vibration levels and longer operating campaigns.

\section{Alignment Procedures}

Alignment procedures were simplified. The motor shaft was aligned parallel to the blower shaft and 0.004 inches lower than the blower shaft. This allowed for the estimated thermal expansion of the motor frame, but was not so extreme as to cause any preload on the bearings in the cold condition. The start-up and long-term vibration levels have been satisfactory since adopting this procedure.

\section{Tilting-Pad Bearings}

Based on the results of the comprehensive rotordynamics modeling, tilting-pad bearings were designed and manufactured for this system. They were installed at the first available opportunity during a scheduled shutdown of the process and were then run with the gear coupling in place. The vibration-versus-time traces of this latest configuration are provided for the blower's outboard and inboard bearings in Figures and, respectively.

Examination of the figures reveals that the vibration amplitudes at both blower bearings are at or below the $1 \mathrm{mil}$, pp, level. This represents a substantial improvement in performance over any of the machines that utilized the original plain cylindrical bearings and is in good agreement with the predictions of the rotordynamic analysis. As of this writing, the machine has run 


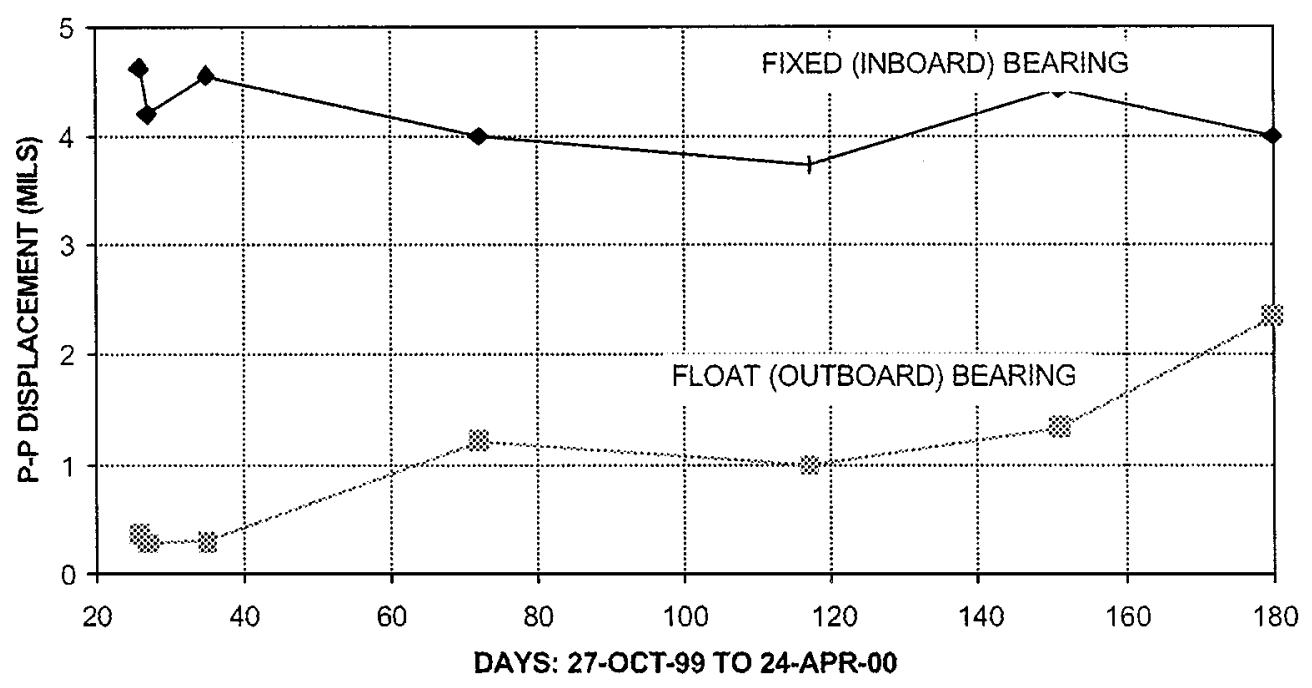

FIGURE 25A

Blower bearing 45-degree right vibration levels: Before.

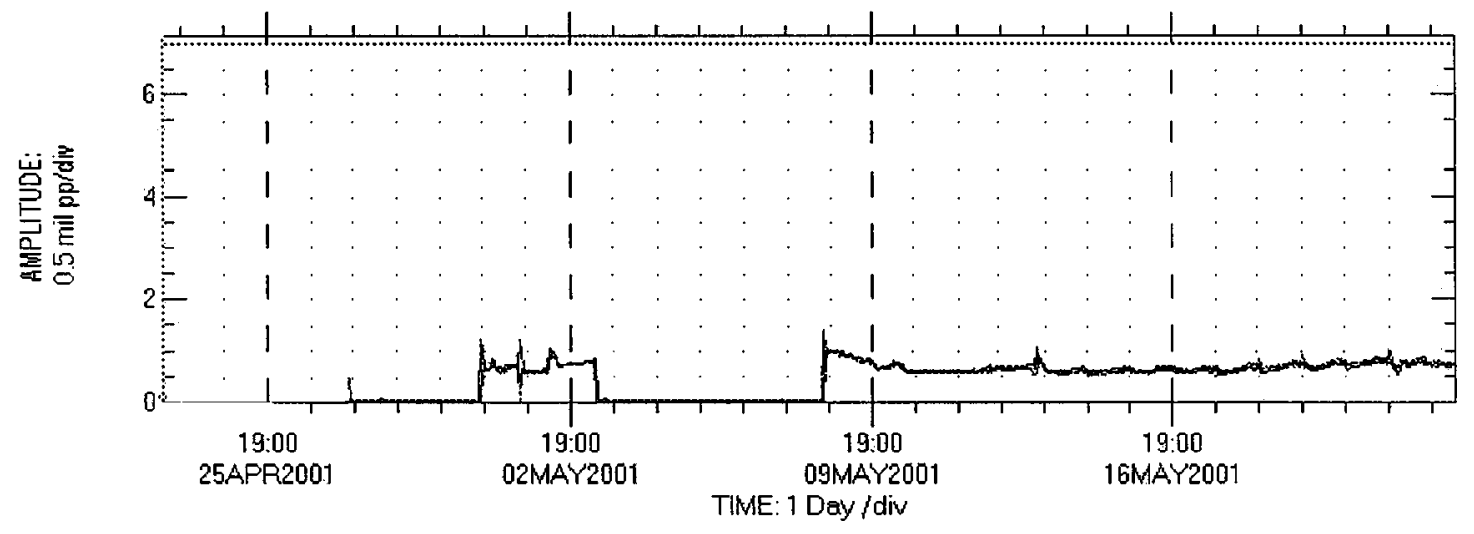

FIGURE 25B

Blower float (outboard) bearing 45-degree right vibration levels: After.

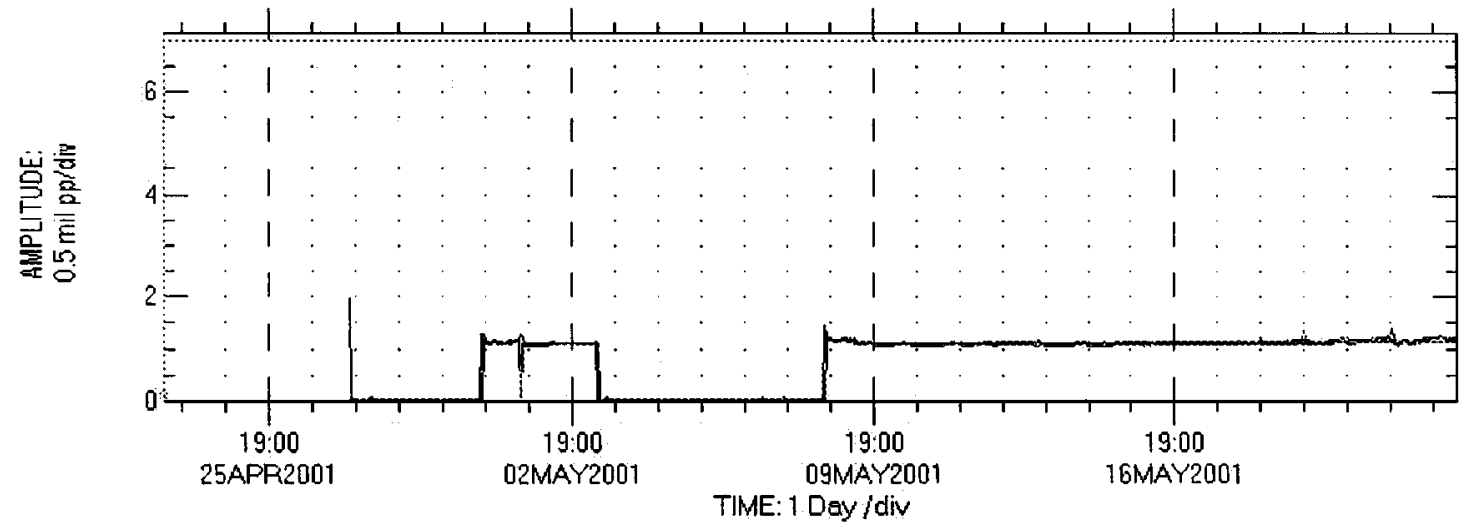

FIGURE 25C

Blower fixed (inboard) bearing 45-degree right vibration levels: After. 
at this relatively low level of vibration for a period of more than 2 weeks, so it appears that the coupling and bearing changes that the rotordynamic analysis pointed to were sufficient to solve this most troublesome vibration problem.

\section{CONCLUSIONS AND RECOMMENDATIONS Coupling}

The high angular stiffness of the metal disk coupling was a problem because of the light radial loading on the blower float (inboard) bearing. This problem has the potential to exist on blowers of overhung design. The change to a coupling with lower angular stiffness resulted in better mechanical separation of the motor rotor from the blower rotor, which in this case (and probably in general) was desirable, as it yielded lower unbalanceresponse vibration levels. The coupling change alone, however, was not sufficient to be considered a complete resolution of the vibration problems.

\section{Alignment Procedures}

Allowance for thermal expansion of one or more rotor supports should be limited to a reasonable range. Excessive cold misalignment (in anticipation of the effects of thermal expansion can exceed the available running clearance in the bearings in the cold condition. This could lead to bearing damage as soon as the system is brought up to speed, before any thermal expansion takes place.

\section{Rotor Dynamics}

An effective mathematical model of a system must be able to accurately predict behavior that is observed during actual operation. In some cases, such as the one described here, that can be accomplished only by means of a rather complex model that incorporates the machine rotor, the coupling, and the driver rotor simultaneously. Once the model predicts the actual performance accurately, the analyst then has confidence that improvements resulting from proposed system changes will likewise accurately affect the behavior of the modified system.

In addition to being complex, this comprehensive model tends to go against conventional wisdom. However, the results have shown that this type of outside-the-box thinking is sometimes necessary when dealing with vibration problems in machinery.

\section{Bearings (Plain Cylindrical Sleeve Bearings vs. Tilting-Pad Bearings)}

For overhung rotors, light radial loading is typical on the float (inboard) bearing. Plain sleeve bearings can have extremely low oil-film stiffness and damping characteristics in such a condition. This can lead to high-amplitude shaft vibration and possible bearing failures. Tilting-pad bearings can be used to address this problem effectively. The preload capability inherent in tiltingpad bearing design, as well as the offset pivots, result in satisfactory oil-film stiffness and damping even in light applied-load situations. This results in reduced levels of shaft vibration and satisfactory bearing life.

\section{REFERENCES}

Air Movement and Control Association. Balance Quality and Vibration Levels for Fans. AMCA/ANSI publication 204-96. Arlington Heights, IL: AMCA.

Corbo, M., and Malanoski, S. 1996, September. Practical design against torsional vibration, Proceedings of the Turbo Machinery Symposium. Texas A\&M University.

Corbo, M., and Malanoski, S. 1998, March. Pump rotor dynamics made simple, Proceedings of the 15th International Pump Users Symposium. Texas A\&M University.

Kelm, R. D. 2000. Preliminary rotordynamic analysis of Robinson blower. 

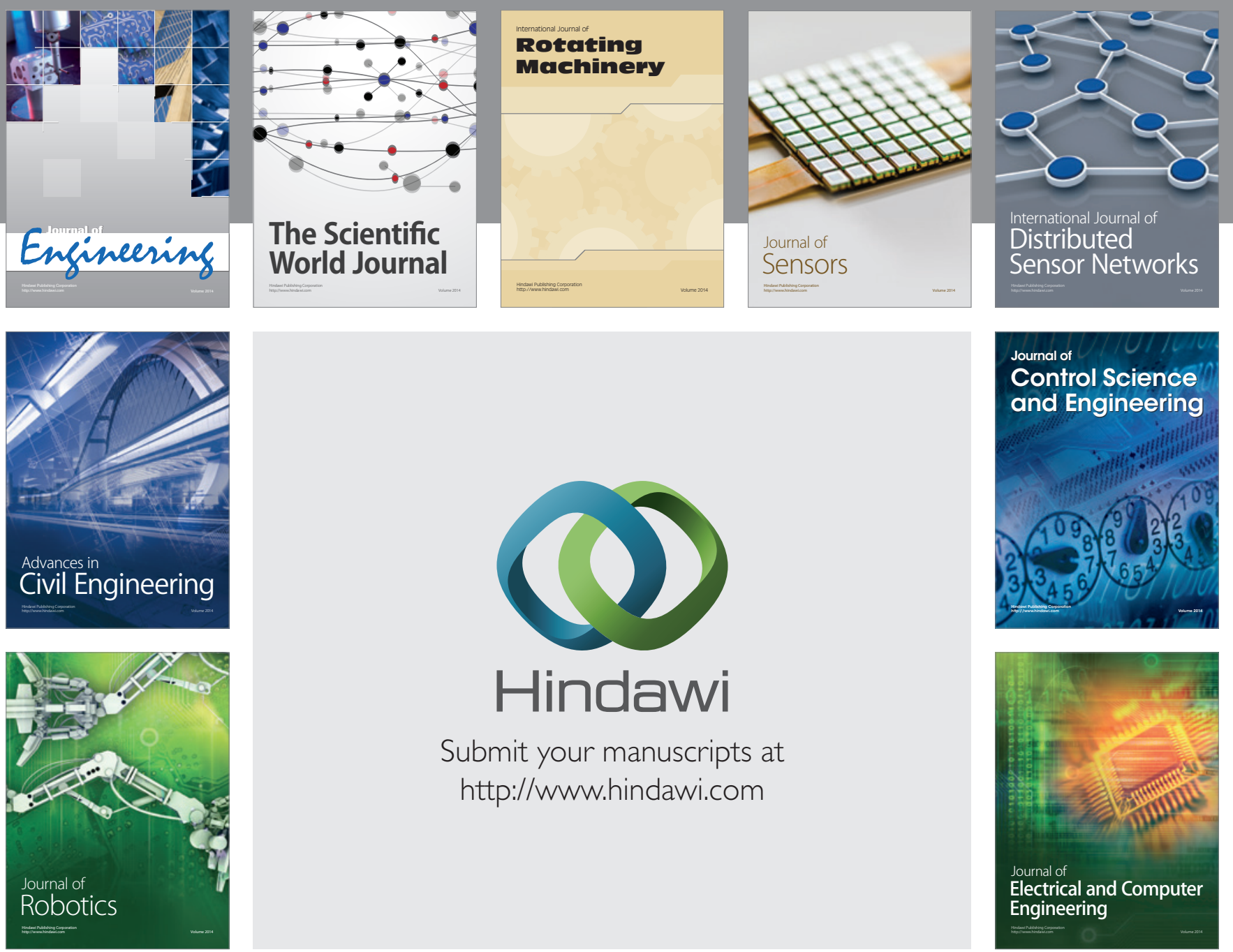

Submit your manuscripts at

http://www.hindawi.com
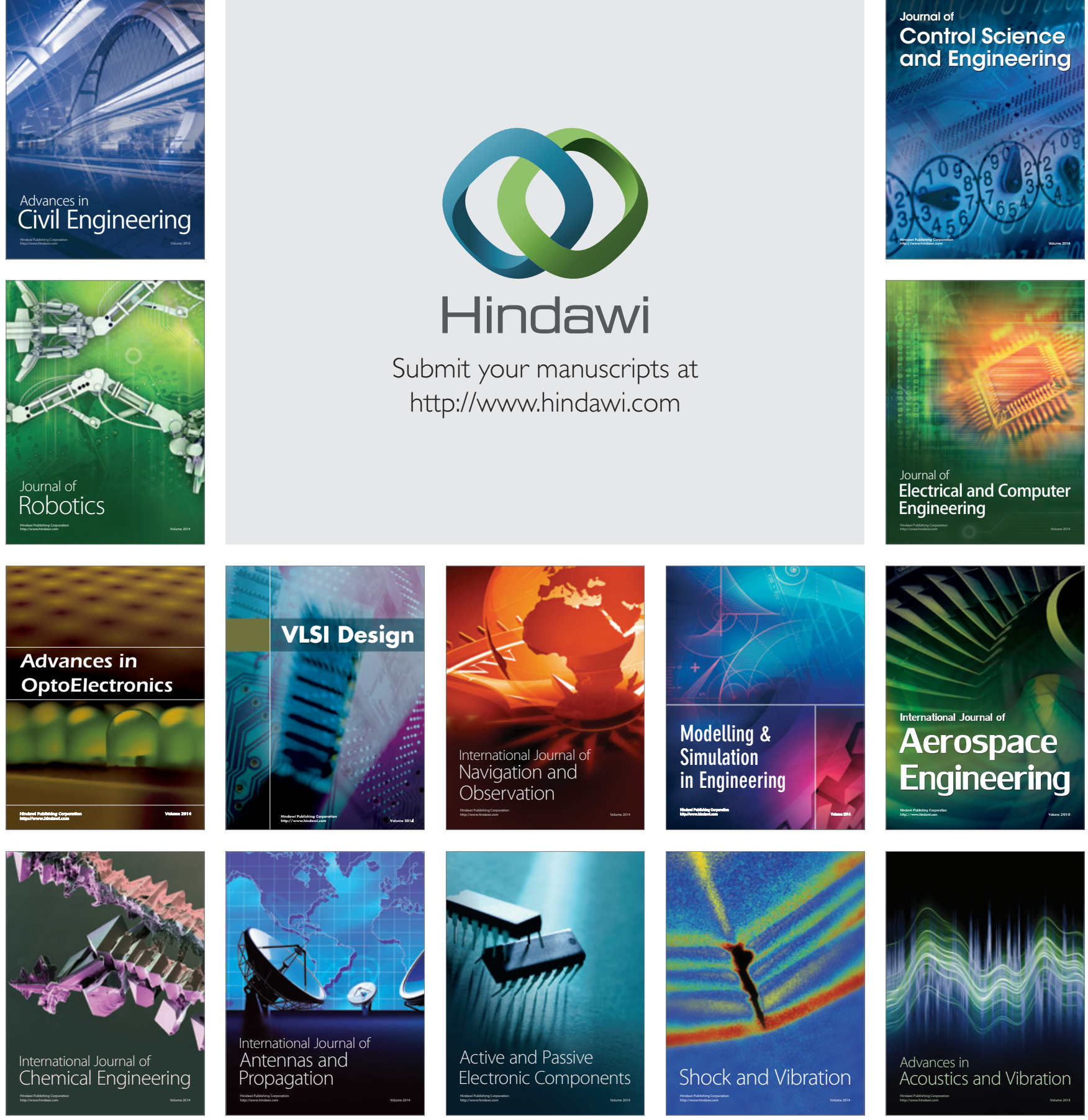